\title{
How Can Experiments Play a Greater Role in Public Policy? 12 Proposals from an Economic Model of Scaling
}

\author{
Omar Al-Ubaydli, Min Sok Lee, John A. List, Claire L. Mackevicius, and Dana Suskind ${ }^{1}$ \\ October 2019
}

\begin{abstract}
Policymakers are increasingly turning to insights gained from the experimental method as a means to inform large scale public policies. Critics view this increased usage as premature, pointing to the fact that many experimentally-tested programs fail to deliver their promise at scale. Under this view, the experimental approach drives too much public policy. Yet, if policymakers could be more confident that the original research findings would be delivered at scale, even the staunchest critics would carve out a larger role for experiments to inform policy. Leveraging the economic framework of Al-Ubaydli et al. (2019), we put forward 12 simple proposals, spanning researchers, policymakers, funders, and stakeholders, which together tackle the most vexing scalability threats. The framework highlights that only after we deepen our understanding of the scale up problem will we be on solid ground to argue that scientific experiments should hold a more prominent place in the policymaker's quiver.
\end{abstract}

JEL codes: C90, C91, C93

Keywords: field experiments; scaling; policymaking

\footnotetext{
${ }^{1}$ We wish to thank Will Aldridge, Nava Ashraf, Jon Baron, Marianne Bertrand, Judy Carta, David Chambers, Jon Davis, Emir Kamenica, Dean Karlan, Scott McConnell, Allison Metz, Norbert Rudiger, and Lauren Supplee for helpful comments on this research agenda. Affiliations: Al-Ubaydli: Bahrain Center for Strategic, International and Energy Studies; Department of Economics and the Mercatus Center, George Mason University. Lee: Department of Economics, University of Chicago. List: Department of Economics, University of Chicago; NBER. Mackevicius: School of Education and Social Policy, Northwestern University. Suskind: Duchossois Center for Advanced Medicine, University of Chicago.
} 


\section{Introduction}

For decades, a small school district in the upper Midwest of the US has been struggling with kindergarten readiness. Administrators have tried a long list of solutions with little success, leaving the District Superintendent, Greta, at her wit's end. A new member of the school board, and devoted follower of the science of early education, Mason recently read an article about an early education field experiment with impressive results: peer reviewed by academic experts, the study showed large treatment effects on several school readiness indicators. At the end-ofthe-year school board meeting, while others discussed the district's woes, Mason brought up the idea of implementing a similar program, a potential silver bullet to address the district's pervasive issues with kindergarten readiness. The benefit cost ratio is astronomical, he assured Greta and the rest of school board. Armed with the science, and associated statistical jargon that few could understand, the school board chose to trust Mason and adopt the program. ${ }^{2}$

That fall, the school district began to introduce the program, rolling it out in an experimental fashion so that officials could credibly isolate the program's impacts and prove its benefits to the community. At every fish fry and rotary club meeting they attended, Greta and Mason mentioned the program. Just wait until these students apply to college - our first Harvard matriculants are coming soon, Mason boasted at the Lion's Club pancake breakfast.

After one year, results arrived. Mason and Greta pored over the costs, benefits, and outcomes, as measured by standardized cognitive and behavioral tests. The results: unequivocally mediocre. The program does not even pass a benefit cost test, much less yield the silver bullet that was promised. I guess the science got it wrong this time, Mason concluded.

But did it?

As academics, we believe that the science likely had it right, but that the results were overinterpreted. The program that Greta and Mason tried to replicate could never carry the water that Greta and Mason had hoped. Indeed, moving from an initial research study to one that will have an attractive benefit cost (BC) profile at scale is much more complex than most imagine.

This is not to focus criticism on field experiments. Quite the opposite, as field experiments have contributed immensely to the "credibility revolution" of the last three decades in the social sciences (see Harrison and List, 2004). In this way, field experiments have become a useful tool to providing causal estimates that are difficult to obtain using other approaches. Yet, while field experiments have focused primarily on testing theories, uncovering mechanisms, and estimating program effects, the question of how to actually use those experimental insights for policymaking remains poorly understood.

\footnotetext{
${ }^{2}$ Except for the names and a few other changes, this is a true story. We trust that readers who work in policy circles or in firms have their own Greta and Mason stories that mirror this illustration. One of the coauthors (List), who worked in the White House from 2002-03, recalls more than a handful of policies going forward in this manner across the various governmental agencies.
} 
One can glean this fact from asking a simple question about the opening vignette: what went wrong in the school district's scaling of the original, successful, field experiment? Maybe the original study was a false positive, whereby the received evidence was not yet actionable? Perhaps there was a "voltage effect" (see, e.g., Kilbourne et al., 2007; Supplee and Meyer, 2015; Supplee and Metz, 2015; Gottfredson et al., 2015; Cheng et al., 2017) because Greta's school district changed core components of the program or failed to hire high quality instructors. The term "voltage effect" or "voltage drop" describes the phenomenon of the measured program benefit in the original research study being significantly larger than the measured benefit when that program is implemented at larger scale. Maybe the cost per student was much larger at scale than at the research site because to hire enough high quality teachers the district had to pay much higher wages than the research study paid their handful of teachers.

Our study is motivated by the goal of digging into the economics of scaling. To date, this literature has largely been devoid of economics, focusing instead on the tools of implementation experts. Yet, a natural progression of the field revolves around the query: how can we combine economics with the experimental method to inform policy at scale? We view this query as the most important question facing evidence-based policymaking today. Indeed, the chain connecting initial research discovery to the ultimate policy enacted has as its most susceptible link an understanding of the science of scaling. ${ }^{3}$ Existing discussions of scaling emphasize fidelity of implementation and identification of core components, with work thus far focusing on certain aspects of the benefit-side, or the "voltage drop" of treatment.

Beyond providing insights into the science of using science (epistemology), we view our work as representing a natural progression of field experiments in the social sciences. In the previous 25 years, field experiments have become an increasingly popular method in economics for providing causal estimates across a variety of settings, addressing issues as far ranging as: why people give to charitable causes; why people discriminate; and why some schools fail to meet standard metrics. The next frontier is to focus more keenly on how we can generate credible and scalable results that policymakers can trust when implementing programs. Providing insights into how results scale to the broader population is critical to ensuring a robust relationship between scientific research and policymaking. Without such an understanding, empirical research can quickly be undermined in the eyes of the policymaker, the broader public, and the scientific community itself.

We augment this literature by introducing an economic lens in two key ways. First, we approach the problem through the lens of economic incentives and markets. By recognizing the various incentives of the actors in the scientific market of knowledge creation, we can understand, recognize, describe, and propose nudges to the important factors that threaten scaling of original research interventions within a logical and coherent economic framework.

\footnotetext{
${ }^{3}$ Following Al-Ubaydli et al. (2019), we view the chain as having three major links: i) funding basic research (see List, 2011b), ii) providing the knowledge creation market with the optimal incentives for researchers to design, implement, and report scientific results, and iii) developing a system whereby policymakers have the appropriate incentives to adopt effective policies, and once adopted develop strategies to implement those policies with rigorous evaluation methods to ensure continual improvement (see, e.g., Komro et al., 2016; Chambers et al., 2013).
} 
Second, we apply economic tools to quantify and clarify changes to benefits and costs when a program is scaled. In this manner, we are effectively shifting the discussion from a purely benefit-driven exploration to one where both benefits and costs are considered, revolving around the problem of the "scale up effect." To our knowledge, little economics has been brought to the voltage question much less to the larger scale up effect problem (yet, the interested reader should see, e.g., Al-Ubaydli et al., (2017a, 2017b; 2019), Ashraf et al. (2018), Banerjee et al. (2017), Davis et. al. (2017), Akram et al. (2017), and Muralidharan and Niehaus (2017)).

As our inspiration, we use the model of Al-Ubaydli et al. (2019). In that study, they created a theoretical framework with three players: i) Government policymakers, which aspires to implement programs that work at scale to maximize expected benefits minus expected costs; ii) Researchers, who desire to report both important treatment effects and replicable findings; and iii) The general populace, which maximizes its utility (or satisfaction). Putting these three players together in a market for scientific knowledge creation, and recognizing the individual incentives of each, provides a useful roadmap that lends new insights into the threats to scalability and points to areas where more empirical work is necessary.

Similar to Al-Ubaydli et al., (2017a, 2017b, 2019), to characterize scalability and highlight certain relevant threats, we divide the problem into three categories. The first involves the statistical procedure applied to the data gathered. This can be viewed as the approach to asking: when is evidence actionable? Publishing a result in a reputable, peer-reviewed journal does not automatically constitute sufficient evidence for a policymaker to be confident that the result represents a "true effect" of the program. Not only do "researchers and policymakers often have different notions of evidence" (Davies, 2012), but there is no one definition of evidence within research or policy worlds. In this first component, we define a notion of actionable evidence to provide guidance to policymakers and researchers (one might argue that premature action is a key issue with scaling; see Ioannidis, 2005, for a review in clinical research).

One proposal from this category is a simple piece of advice to policymakers: we need more precise statistical summaries, and more frequent replication to help address inference problems. We advocate that a post-study probability of at least 0.95 is achieved before enacting policies. In practice, this amounts to three or four well-powered independent replications of the original finding. This is, of course, ad hoc, but will naturally lead to demand for a greater number of replications and a subsequent change in our research reward structure. In equilibrium, more dollars for replications from funding agencies would be a natural outcome. This landscape change would be welcome given the current credibility crises in science (Jennions and Moller, 2001; Ioannidis, 2005; Bettis, 2012; Nosek et al., 2012, Camerer et al., 2016).

Second, the model discusses representativeness of the population, which surfaces continuously throughout the empirical literature as a general topic in the social sciences. Following the vignette above, in the original study, the researcher might have sought a population that minimized participation costs, or perhaps a population that had characteristics that might yield a larger treatment effect (a "let's give the idea its best shot of working" approach). Greta's 
school district might have had students with much different characteristics, including observables like demographics and educational background that did not match the original study. Maybe even the school district had a random sample of children, but the original research did not. In a nutshell, researcher choice/bias, selection bias/sorting of the study's population into the program, non-random attrition, and (dis)economies of scale in participation costs all affect the representativeness of the population studied and this might impact the promise of scaling (see Bell and Stuart, 2016).

Our third category of threat involves a summary of issues surrounding representativeness of the situation. While the focus of the implementation science literature has been program fidelity, situational features in practice are much richer, and we discuss various aspects of the situation that have implications for scalability of the BC ratio. Indeed, the research and policy communities oftentimes generalize results to both a population of situations and a population of people, even though we often only speak of the latter. This is particularly troubling considering that the data, thus far, suggest that representativeness of the situation is much more important than representativeness of the population (see, e.g., List, 2006).

For instance, when Greta's school district scaled up the kindergarten readiness program, they did it within their infrastructure, which might have been entirely different from that of the original study. If the original results are dependent on the specific context, or are not done in a policy relevant environment, we can expect the $\mathrm{BC}$ profile to change at scale. The implementation literature sometimes calls this context-dependence. Likewise, in conjunction with curriculum specialists, the original researcher created a curriculum for pre-kindergarten program, trained the teachers, and provided hands-on support throughout the program. When the school district scaled up the program, they might not have used the exact same curriculum and care as the original implementation due to local constraints. This is often described as "program drift" in the literature.

Another key aspect of the situation pertains to spillovers (network effects) and general equilibrium effects of scaling. Concerning the midwestern school district, spillovers could be negative from the treated group to the control group. While the intervention improves the school performance of students in a given class, the control group may, upon seeing an initial improvement in the performance of the treated group, feel demoralized, inducing a deterioration in their performance, accentuating the measured treatment effect (psychologists denote this effect as "resentful demoralization"). Of course, the effect could run in the opposite direction. For example, List et al. (2019) provide such an example in their measurement of the effects of a pre-K intervention in Chicago: control group children gain more than 0.5 standard deviations in cognitive test scores based on proximity to treated neighbors. This implies at scale the program may be much more effective than the original research suggests. Such spillovers can also occur within treatment or control groups, positively or negatively magnifying effects. In addition to within- and between-treatment spillover effects, there is also the possibility of spillovers from the treated group to people who are not even participating in the experiment, i.e., people beyond the control group (the interested reader should see Banerjee et al. (2017) and Muralidharan and Niehaus (2017)). 
Representativeness of the population and the situation as potential threats to scalability underline how fundamental it is to understand "sites" (i.e., the environment where the original research was implemented) to address the scale up problem. The literature treats "sites" loosely where some disciplines focus on the population of sites while others emphasize the situational characteristics. We define "sites" as having multi-dimensional characteristics, which our theory guides into population and situational categories. It is, thus, critical for researchers to comprehensively describe the environment where the research is carried out, going beyond a cursory description.

We do not view our insights as limited to helping policymakers. By highlighting the key potential economic sources threatening scalability of programs and bringing them to the attention of researchers, we hope that those preparing to conduct new studies might consider modifying their own designs such that their reported treatment effect estimates more accurately inform what is likely to occur should the program be scaled. In this way, the new demand on scholars is that we backward induct when setting up our original research plan to ensure accurate and swift transference of programs to scale with minimal uncertainty.

In this manner, our research advocates flipping the traditional knowledge creation model, calling on scholars to place themselves in the shoes of the policymakers whom they are trying to influence. While we put forward 12 proposals that span researchers, policymakers, funders, and stakeholders, our general call is for policy research that starts by imagining what a successful intervention would look like fully implemented in the field, applied to a policyrelevant subject population and situation, sustained over a long period of time, and working as it is expected because its underlying mechanisms are understood.

The remainder of our study proceeds as follows. Section 2 defines the scale up effect and provides an overview of select interventions that worked successfully at scale and interventions that show less evidence of success at scale. Section 3 defines the knowledge creation market and outlines the theoretical model. Section 4 highlights predictions from the model and summarizes our 12 proposals. We conclude with a summary highlighting the import of understanding the science of using science.

\section{Defining the scale up effect and summary evidence of scaling exercises}

Policymakers inform policies through results from programs that have high, attractive $\mathrm{BC}$ measures. This evidence often comes in the form of a large measured treatment effect, or benefit, in a small-scale randomized controlled trial (RCT). ${ }^{4}$ In policymaking and the scientific community, it is considered a disappointing surprise when large-scale policy implementation does not result in the same benefit profile as a small-scale RCT program evaluation. The implementation literature refers to this problem as the voltage effect. To avoid confusion

\footnotetext{
${ }^{4}$ Policymakers do not exclusively consider RCTs as evidence to inform policies (just as researchers do not only run RCTs to evaluate programs), but our study focuses on RCT-generated evidence.
} 
between the voltage effect, and the gross scaling effect, which also considers the cost side of the equation according to our definition, we use a new term, scale up effect, which refers to changes in the net treatment effect resulting from changes in scale. That is, we include both benefits and costs when considering scaling. In the next sections, we disentangle the scale up effect into mechanisms through which the benefits and/or costs change from small to large scale. Each mechanism is categorized into one of our three categories.

The scale up effect can also be interpreted broadly within the context of generalizability of experimental results (Al-Ubaydli and List, 2013). In most cases, many scholars view generalizability as "horizontal scaling," or whether the empirical results generalize across space and time. Alternatively, the scale up effect is "vertical scaling," or whether the measured BC profile calculated in small scale RCTs can be generalized to larger scale environments.

While we view our economic approach to the scale up problem as having several novel elements, we are not occupying virgin territory. Many entities involved in the generation of scientific knowledge have acknowledged the importance of the scale up effect in their framework, though there are no uniform broad guidelines on how to address them. For example, the Institute of Education Sciences' (IES) five goals are a useful framework within which to consider the scale up effect in education. Their Goal 4, Effectiveness, is the stage at which research determines whether programs will be effective within "routine practice in authentic education delivery settings," or whether effects of a program remain even in a more natural context. ${ }^{5}$

Similarly, using the Institute of Medicine (IOM) T0 to T4 translational research framework, our model describes the progression from T2 to T3 and T4. ${ }^{6}$ Likewise, in the language of the NIH National Center for Advancing Translational Sciences, we focus on research moving from the 'Clinical Implementation' to the 'Public Health' stage, where researchers attempt to bring promising interventions to a wider population. ${ }^{7}$ The $\mathrm{NIH}$ emphasizes the distinction between efficacy trials that mirror our idea of program evaluation before effectiveness trials that describe our policy scale up (Bauer et al., 2015). Finally, the Food and Drug Administration (FDA) has a rigorous 5-step drug approval process. Our model of scale up is similar to their Step 3, Clinical Research, to Step 5, Post-Market Safety Monitoring. ${ }^{8}$ Our focus is social programs that may become policy, while the FDA is dedicated to medical drugs, but the approach is similar--we chart the process from small-scale research to large-scale effectiveness.

\section{Summary of scaling evidence}

Across different disciplines, there are examples of RCTs or program evaluations that have been successfully implemented at scale. However, these are the minority. In the cases of both

\footnotetext{
${ }^{5}$ https://ies.ed.gov/director/board/briefing/ncer_structure.asp

${ }^{6}$ https://ictr.wisc.edu/what-are-the-t0-to-t4-research-classifications/

${ }^{7}$ https://ncats.nih.gov/translation/spectrum

${ }^{8} \mathrm{https} / / /$ www.fda.gov/ForPatients/Approvals/Drugs/default.htm
} 
successes and failures, our theoretical framework aids in explaining, or hypothesizing about, the potential causes of these outcomes.

The Knowledge is Power Program (KIPP) network of charter schools is an example of successful scaled up implementation of an initial RCT evaluation. Early on, it had shown promising positive results on student achievement at smaller scales (Angrist et al., 2012; Tuttle et al., 2013), and the main empirical results were replicated in larger-scale RCTs (Tuttle et al., 2015; Knechtel et al., 2017). Our theory described below suggests that these results are not surprising, as across this horizontal scaling, the key mechanisms driving the scale up problem were turned off: representative population of students who typically attend the schools, fidelity of curriculum implementation, infrastructure, quality of teachers, etc. If KIPP is further scaled, the theory pinpoints several potential threats: long school days and school year (implementation cost), selective teacher hiring (implementation cost) and selection of students into KIPP (selection bias/sorting), among others.

Another successful scaling example is the California Greater Avenues for Independence (GAIN) welfare-to-work program in the late 80s and early 90s. In an initial RCT in six counties in California, one of the counties in particular (Riverside County) showed promising results in increasing employment and earnings of the participants (Riccio et al., 1994; Freedman et al., 1996). A few years later, this same model was implemented in the much larger Los Angeles County, and the positive effects on employment and earnings were replicated at scale (Freedman et al., 2000). Although it is difficult to pin down the exact reasons for this success, the continuous involvement of the Department of Public Social Services in charge of the overhauling of the program played a key role in shutting down the potential mechanisms that threaten scalability. This points to the importance of the involvement of the original scientist/implementor, as we suggest below.

While these examples highlight successful scaling cases, results of program evaluations that were not replicated in larger scale RCTs, or when implemented at a larger scale by policymakers, appear more numerous in the literature. Some of these unsuccessful examples belong to what our model describes as the statistical inference problem. Collaborative Strategic Reading (CSR) is a program designed to increase reading comprehension that in quasiexperimental settings showed positive results. However, Hitchcock et al. (2011), in an RCT, find no meaningful effect of the scaled program. Project CRISS, a teacher professional development program designed to improve students' literacy, had initial positive results in an early, small sample RCT (Horsfall and Santa, 1985). These were overturned in a more rigorous, larger RCT (Kushman et al., 2011). According to Straight Talk on Evidence, and across disciplines ranging from business to medicine, education to employment training, between $50 \%$ to $90 \%$ of results fail to replicate. ${ }^{9}$ These would have been examples of premature action had policymakers decided to scale up these programs based on the early positive results, which

\footnotetext{
9 https://www.straighttalkonevidence.org/2018/03/21/how-to-solve-u-s-social-problems-when-most-rigorous-programevaluations-find-disappointing-effects-part-one-in-a-series/
} 
emphasizes the importance of using metrics such as the post study probability (Maniadis et al., 2014) that we describe below.

Exploring data from a non-representative population is our second category of potential threat to scalability. One example is a policy that approved the sale of iron-fortified salt to the general public in India based on positive results of studies that focused on adolescent women. Banerjee et al. (2015) find that the fortified salt had no effect on the policy goal of reducing general anemia (even though they do observe effects on the group targeted (adolescent women) by previous studies). This is an example where the policy did not consider the representativeness to the broader policy population. In other cases, a subsequent evaluation was not carried out, but aspects of the initial RCT suggests that the results are unlikely to be replicated if the program was implemented at a larger scale.

A different group of unsuccessful implementations can be linked to situational unrepresentativeness. After promising initial results from the Tennessee STAR project that reduced class sizes, a series of implementations failed to replicate its success. In line with STAR, Tennessee rolled out two initiatives, Program Challenge and Basic Education Program but neither of them replicated the earlier results (Hippel and Wagner, 2018). In the former program, the resources were not used to reduce class size (i.e., wrong program) and in the latter program, class size reduction was negligible (i.e., wrong dosage).

California tried its class size reduction program statewide. However, for its implementation it had to hire many more teachers than the original research, and this led to the hiring of teachers with little teaching experience or full certification compared to the initial STAR project (Jepsen and Rivkin, 2009). As the above examples highlight, fidelity of implementation is a key scalability threat (see also Kilbourne et al., 2007; Supplee and Meyer, 2015; Supplee and Metz, 2015; Gottfredson et al., 2015; Cheng et al., 2017). A survey report by the U.S. Department of Education (Crosse et al., 2011) shows that among the prevention programs attempting to attenuate youth substance abuse and school crime implemented during the 2004-05 school year, only $8 \%$ of them were backed by reasonable research evidence, and shockingly of those $8 \%$ more than $50 \%$ had not met fidelity standards in their implementation.

These examples show the import of the scale up problem but, more subtly, they also draw our attention to the roles played by different stakeholders in the knowledge creation market in contributing to this problem. The incentives of the different agents must be aligned if we want to address this problem. We turn to this market next.

\section{The knowledge creation market and the model}

Scaling promising programs into effective policies is a complex, dynamic process. We follow Al-Ubaydli et al.'s (2019) framework to model the scale up problem to provide guidelines for researchers and policymakers across disciplines to more effectively approach scaling. The market for science-based policy has three major players, as shown in Figure 1. 


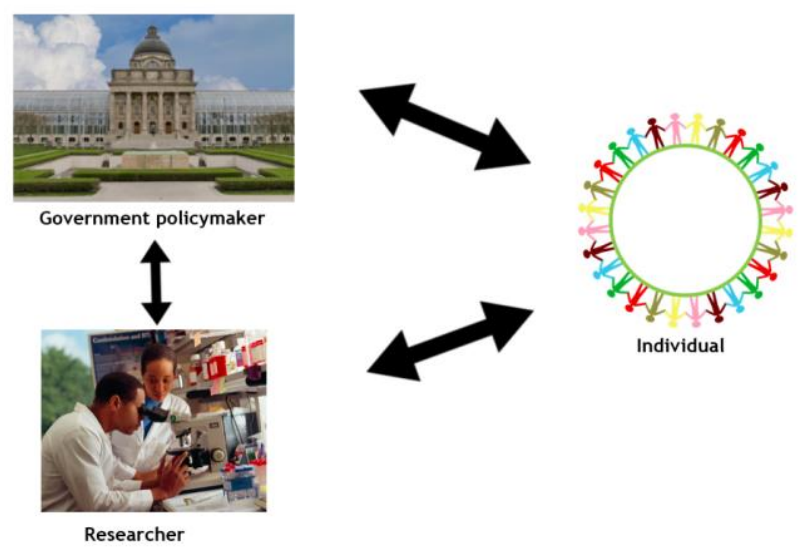

Figure 1. The Knowledge Creation Market

Policymakers implement policies that they expect will provide the greatest benefit to the population within time, money, and resource constraints. Their expectations of benefits and costs are based on small-scale program evaluations, measured using BC analysis, though, sometimes, this analysis is limited. The policymaker decision-making process is the basis for our model of scaling.

Researchers conduct experiments to generate data to evaluate programs and publish research. They observe individual characteristics of those who participate in the experiment, as well as characteristics of the situation in which the experiment is conducted. The researcher maximizes their own personal benefits, which include considerations specific to academia, net of the costs associated of running the experiment.

Individual citizens receive benefits from the programs the government implements and receive rewards for participating in research studies. These rewards are balanced with costs they accrue from being experimental participants.

We now take a closer look into aspects of the model and subsequent results from Al-Ubaydli et al. (2019).

\section{Nuts and bolts of the Al-Ubaydli et al. (2019) model}

A policymaker aims to implement a policy that has the largest net benefit at policy relevant scale and environment. In other words, the policymaker's objective function is defined as expected policy benefits minus expected policy costs at scale. ${ }^{10}$ However, because the policymaker does not know the true net benefits of a potential policy, he must rely on estimates

\footnotetext{
${ }^{10}$ We acknowledge that policymakers do not always have as their goal to maximize benefits to the population and might focus instead on policies that maximize reelection probabilities or equity or many other outcome metrics. This is an important factor, but it is not within the scope of Al-Ubaydli et al. (2019), and does not affect our general results.
} 
from program evaluations. In the model, we assume that the policymaker, similar to Greta and Mason in our opening vignette, naively accepts benefit and cost estimates provided by the researcher.

A researcher runs a field experiment with a chosen environment to generate data to evaluate the program. She observes individual characteristics of those who participate in the experiment, as well as characteristics of the situation in which she implements the experiment. The researcher maximizes her personal benefits net of the costs associated with running the experiment. The researcher's objective function has three benefit components:

1. She wants to conduct an experiment with results that can be independently replicated, which is rewarded with reputational capital in the research community.

2. She wants to conduct an experiment with large estimated net benefits, which will be more likely to be published in an academic journal, yield professional rewards, including tenure, higher salaries, greater likelihood of a grant, etc.

3. She wants her research to be implemented at scale, which is rewarded by prestige and other benefits including consulting jobs, wider exposure, and the positive feeling that she is helping to change the world.

These assumptions raise an initial red flag in that there is an inherent conflict: replicability is potentially at odds with the latter two components. This is because the researcher chooses her subject pool (and the situation). As such, with superior knowledge regarding the unique attributes of the participants compared to other scientists and other parties who were not involved in the experiment, for example, she can strategically choose a sample population that yields a large treatment effect if she so wishes.

In addition, if subjects with the largest expected benefits from the program are more likely to sign up, participate, and comply, a scientist who maximizes her sample size subject to a fixed budget constraint inadvertently is maximizing the treatment effect, and subsequently presenting results that may not scale. This selection effect is a key assertion in the model and drives important results on the representativeness of the population.

As Al-Ubaydli et al. (2019) note, the medical literature features significant support for this assumption. Meta studies of recruitment confirm that those who stand to benefit most from a medical treatment are more likely to participate in trials. For example, in Cooper et al. (2015), recruitment for medical treatments for type 2 diabetes was significantly easier than for prevention interventions, due to the size, tangibility, and immediacy of the effects of the former. While factors such as altruism and the desire to save money are important determinants of an individual's readiness to participate in a medical trial, surveys also indicate that perceived benefits are critical, often because prospective participants assume that the medical treatment in a medical trial is of higher quality than conventional, non-experimental treatment (Walsh and Sheridan, 2016). 
After conducting experiments, scientists submit their estimated net treatment effects to scientific journals for publication. Consumers of scientific journals demand studies that report novel and large net treatment effects. They reward journals via the purchase of subscriptions and by citing the papers within a journal. Within the model, these two goals are perfectly aligned.

Government policymakers naively read results reported in the academic literature - they do not account for potential estimation bias, unrepresentativeness of the participants and situations in published studies, economies of scale, and spillovers. The overarching key to the model is that the policymaker cannot observe characteristics of participants or the situation, so he has a limited ability to predict how the small-scale effects might change when the population and situation changes at scale. In a research world where replication is ill-rewarded and academic journals focus on surprising results, the model implies that researchers' direct choice of their sample population contributes directly to the scale up effect. In other words, there can be a scale up effect even when there is no nefarious researcher behavior.

The model highlights three areas that represent key ingredients to understanding the scale up effect, or the threats to scalability of experimental results: i) what constitutes actionable evidence (inference)? And how the properties of the ii) population and iii) situation affect scaling. The situation is incredibly rich and includes spillovers and general equilibrium effects at scale. Within these three areas, six possible sources of the scale up problem exist:

1. The statistical estimation error (which we refer to as a statistical inference problem).

2. The participant being unrepresentative of the population in terms of direct treatment effect.

3. The participant being unrepresentative of the population in terms of participation cost.

4. Economies/diseconomies of scale in participation costs.

5. Economies/diseconomies of scale in implementation costs.

6. Spillover and administration quality impacts direct treatment effects.

An additional effect is that there might be general equilibrium effects of the program at scale. We will define these later and match them with spillovers in the discussion below.

\section{Implications of the model: inference, population, and situation}

In this section, we place these 6 sources into our three categories: inference (source \#1), population (sources \#2, \#3, and \#4), and situation (sources \#5 and \#6). These three categories represent an intuitive way of categorizing the threats to scalability and relate to the threats identified by the literature across disciplines. We discuss each in turn and tie them directly to results in the Al-Ubaydli et al. (2019) model. We also describe additional sources of the scale up effect that are not captured in the parsimonious theoretical model but are relevant to researchers and policymakers. Sometimes, we break up the above source into mechanisms to fully capture the breadth of the threat. For each of the three categories, we provide examples from the field where they had or might have had a role as a threat to replicability and scalability. 


\section{A. Inference}

Are we making the correct inference from our data? At its most basic level, one might argue that too many programs are scaled before there is actionable evidence. An example of such a situation is potentially our opening vignette, or several of the empirical examples of unsuccessful scaling in Section 2. Alternatively, one might argue that not enough interventions are scaled, and when they are put to use they are scaled too late. ${ }^{11}$ This debate naturally begs the question, when is evidence actionable? Put another way, what is "evidence-based policy?"

In our discussions with policymakers and researchers around the world, evidence-based policy is perhaps the most elusive of concepts to define. Yet, what is clear is that policymakers want to claim that they use evidence, as the following quotes show:

"...the use of evidence and evaluation to ensure we are making smart investments with our scare taxpayer dollars"

$\sim$ President Obama (2013)

"Policy innovation and evidence-based policy making is at the heart of being a reformist government"

$\sim$ Prime Minister Kevin Rudd (2008)

"The ministries are responsible for effective use of public funds... cost benefit analysis is the most important tool for good decisions, but we observe that it is performed too few analyses and that the quality is varying"

Marianne Andreassen, (Hamarsland, 2012)

Our model attempts to put some rigor around the notion of inference and evidence. It begins by adopting the Bayesian approach for updating the probability that a finding is true (PSP), outlined in Maniadis et al. (2014), where:

$$
P S P=\frac{(1-\beta) \pi}{(1-\beta) \pi+\alpha(1-\pi)}
$$

PSP: Probability that the research finding is true.

$\alpha: \quad$ Level of statistical significance

$1-\beta$ : Level of power

$\pi$ : Prior

This approach takes a strong stand in that it eschews the traditional method of relying on only one metric — statistical significance - to judge evidence of efficacy, and proposes a more complete statistical story, made up of the Three P's:

$i$. $\pi$, the prior: Evaluating results from a research study could cause someone to change her previously-held belief that a certain program causes particular outcomes. ${ }^{12}$ A previously-

\footnotetext{
${ }^{11}$ When Dean Karlan served as our discussant at a recent conference this was his basic message.

12 See also Wacholder et al. (2004) and Ioannidis (2005).
} 
held belief is her prior, or pre-study probability. The evaluator updates her prior based on new information, in this case results from an RCT, and adjusts her belief about the program's effectiveness to obtain the post-study probability (PSP).

ii. $p$-value: The results of a study are often reported as statistically significant if $p$-values fall below a predetermined threshold (e.g., 0.05). The p-value is a continuous metric between 0 and 1 that measures the compatibility of observed data with the assumed model, or the null hypothesis that there is no treatment effect. A p-value smaller than 0.05 is commonly misinterpreted as "the probability of the effect being a false positive is less than $5 \%$," or that there is a less than 5\% chance the null hypothesis of no effect is true. The correct interpretation of a p-value of less than 0.05 is that, over many studies, there is less than a $5 \%$ chance that the result found is a false positive, given that the model and other assumptions are correct. ${ }^{13}$

P-values may also be incorrectly reported. Each individual finding in a research study is considered a hypothesis that is being tested to measure whether the null hypothesis of no effect can be rejected. Each of these hypotheses has its own p-value. For one study, there may be multiple hypotheses tested (multiple treatments, multiple subgroups, etc.). Rather than considering each hypothesis in isolation, researchers should adjust for multiple hypothesis testing (MHT) to account for the statistical likelihood that any one finding might be a false positive. ${ }^{14}$

P-values should be used to update priors, not as conclusive evidence of a program's effectiveness. A single, very low, correctly-reported p-value from one outcome in an RCT should not be the sole or even primary basis of policy. Over many iterations of evaluating evidence of a program, a person can be more confident that she is updating her priors appropriately.

These issues are magnified by publication bias, ${ }^{15}$ the practice in which journals overwhelmingly publish studies that have large, surprising results with low p-values. These are published more often than small, unsurprising, and/or null results, despite the fact that studies with those characteristics can and should help update priors. It is important for policymakers to be aware that the research presented in journals is curated in this way.

iii. power: The power of a study is a measure of the likelihood that the study finds an effect when that effect is indeed present. It is calculated before a study is run, using the number of participants in a study, characteristics of the measured outcome, and a specified minimum detectable effect size. For example, a study with a power of 0.80 is one in which $80 \%$ of the time, given a certain number of participants and characteristics of the outcome measure, that study will be able to detect the prespecified effect size if it is repeated many times.

\footnotetext{
${ }^{13}$ For a comprehensive treatment see Greenland et al. (2016) and Czibor et al. (2019). Deke and Finucane (2019) and Kaplan (2018) also provide a description of this issue that are friendlier to the general audience. 14 See, e.g., List et al. (2016) for an MHT approach with experimental data.

${ }^{15}$ See Stanley et al. (2013), Christensen and Miguel (2018), Andrews and Kasy (2017), and Young et al. (2008).
} 
Low-powered studies fail to detect an effect even if that effect is present. This false negative, or Type II error, can cause someone evaluating a study to prematurely write off a program as ineffective. When a study is low powered, the measured benefit of the study indicates that there is no effect present, and a policymaker might assume the program is ineffective. In reality, the study may have had too few participants for the study to identify the effect.

Results of low powered studies can also importantly overestimate the size of an effect, ${ }^{16}$ so if a program is implemented elsewhere the measured effect of that implementation will be smaller than the original implementation. Only programs that overestimate the size of an effect will appear to be statistically significant when a study is low powered, which is merely a result of statistical noise. A general insight from this literature is that sparsely populated experiments can lead to higher treatment effect estimates simply due to chance induced by low power.

\section{Insights from the model on inference}

With the above machinery in place, a first insight from the Al-Ubaydli et al. (2019) model is that there can potentially be a scale up effect in the short run even when there are many scientists exploring the problem. Indeed, the economic reader might notice the parallel with the "winner's curse" literature describing bidding patterns in auctions. That is, bidders typically do not adjust their optimal bids appropriately when more bidders enter the auction (they should bid lower amounts, see Harrison and List, 2004). The same phenomenon is happening hereas the number of scientists working on related programs increases, the "winning program" will be overly optimistic due to randomness, leading to a greater inferential error. This is most commonly described as a 'false positive,' or Type I error.

A second insight from the model is that the PSP can be raised substantially if the initial positive findings pass as few as two or three independent replications. This is an important insight, because in our experience some decision makers in government and the private sector wish to rush new insights into practice. Proper incentives for independent replication therefore help mitigate the scale up effect. This leads to our first proposal:

PROPOSAL 1: Before advancing policies, the post-study probability should be at least 0.95. In cases where the prior $(\pi)$ is ill-understood, we recommend assigning a conservative choice of 0.1 in "surprise result" cases and 0.5 when results are broadly anticipated. ${ }^{17}$

\section{In Sum:}

In a small-scale RCT, the inference problem causes the measured treatment effect of a program, the benefit side of the $\mathrm{BC}$ metric, to misrepresent the actual effect of a program. Erroneous

\footnotetext{
16 This is also known as effect inflation (Button et al., 2013), the winner's curse (Young et al., 2008) or the Type M error (Gelman and Carlin, 2014).

17 The spirit of this proposal is contained within FDA guidance, where the U.S. Department of Health and Human Services notes "at least two adequate and well-controlled studies, each convincing on its own, to establish effectiveness" of a new drug (p. 3, "Guidance for Industry Providing Clinical Evidence of Effectiveness for Human Drugs and Biological Products").
} 
statistical inference can occur independent of scale, but is more likely with low powered programs. The scale up effect becomes evident when a certain intervention tested in a small scale RCT suffers from an inference problem and then is implemented at a larger scale and shows no (or much smaller) effect. The inference problem is twofold:

1. A research study finds an effect, but that finding is just statistical noise. This is most commonly described as a 'false positive,' or Type I error.

2. Effects in a study are not correctly reported, or after appropriate adjustments measured effect estimates lose statistical significance. One common case of incorrect reporting occurs when analysis does not control for multiple hypothesis testing. ${ }^{18}$

Talking about replication in the context of scale up problem naturally raises the question of what "replication" is. For example, if the initial positive effects of a program implemented for low income individuals do not sustain when implemented for high income individuals, it is technically incorrect to conclude that the initial program failed to replicate. It is beyond the scope of this study to delve into the minutiae of replication, but regarding inference, by "replication" we mean an implementation of a new RCT that matches the initial RCT as close as possible. Most, "replication" implementations in the social sciences do not fall under this narrow definition of replication. These new implementations can be interpreted as adding two new information: $i$ ) information on inference for the updating of the PSP (coming from the portion that matches the initial RCT), and ii) information on the effectiveness of the intervention for a broader range of populational and situational characteristics beyond the initial RCT.

\section{Examples:}

Premature implementation of interventions that do not have a high PSP (i.e., replicated enough) poses a major threat to scalability. Over a series of scientific replications of a Collaborative Strategic Reading (CSR) intervention in 5 different districts in Oklahoma and Texas, Hitchcock et al. (2011) find that overall the program has no effect on reading and comprehension. They demonstrate that the CSR program that showed initial promising results was not effective in other states.

Another example is Project CRISS, a teacher professional development program designed to improve students' literacy. An early RCT (Horsfall and Santa, 1985) showed large effects on reading achievement but the study displayed some warning signs: it had a small sample, increasing the probability of a false positive, and the researchers created their own outcome measures. Unsurprisingly, when CRISS was reevaluated in a larger, government sponsored RCT the positives results were overturned (Kushman et al., 2011). Although other mechanisms could have been at play, we suspect that the early results were false positives. ${ }^{19}$

\footnotetext{
${ }^{18}$ For a more comprehensive assessment, see Deaton and Cartwright (2017).

${ }^{19}$ The interested reader should see Jon Baron's excellent work on "Straight Talk on Evidence," which discusses many more examples of false positives.
} 
In their paper about adjusting experimental results when testing multiple hypotheses, List et al. (2016) point out that a few of the secondary treatments of a charitable giving experiment (Karlan and List, 2007) lose significance if the analysis is adjusted for MHT. Even results published in top academic journals can suffer from an inference problem due to incorrectly reported results.

In their discussion of low-powered studies, Button et al. (2013) find the median power in a meta-analysis of neuroscience papers is (conservatively) 21\%, implying that "the likelihood that any nominally significant finding actually reflects a true effect is small." Thus, it is critical for the analyses to include power calculations, and a deeper understanding of the related issues with low powered studies should always be a discussion point.

\section{B. Representativeness of the Population}

Did we have the "correct" people in the original research study? This is an area of inquiry that policymakers are well aware of, and one that at least on traditional individual-specific observables - gender, race, age - they keep close tabs. Scholars have also made important inroads in these dimensions too (Bell and Stuart, 2016; Stuart et al., 2018), lending important insights into heterogeneity (Heckman et al., 1998) and the effects of non-random attrition (see, e.g., Ogutu et al., 2018). Yet, there are in many cases invaluable pieces of information that the researcher has that the policymaker might not have at her disposal or that it might be difficult to obtain. The model adds rigor around the notion of representativeness of population and its impacts on scaling, creating the following mechanisms through which unrepresentativeness of the population can contribute to the scale up problem:

i. Researcher choice/bias: Researcher choice/bias causes the scale up effect through the benefit and/or cost sides of the BC metric. A program's effect may be dependent on characteristics of the population receiving the program. When a researcher seeks out a particular population for her study - whether for convenience, interest in securing a promising first result, or other reasons - she is employing choice/bias. This may result in the certain group of subjects in her RCT showing different characteristics than the policy-relevant population, and those characteristics could impact the measured treatment effect of the evaluation. Researcher choice/bias does not primarily come from a nefarious desire to overestimate effect of a program.

Additionally, researchers may seek out a specific population that will benefit greatly from the program in order to show large and significant effects, which could increase the chance of journal publication, traction for further studies, and possibly traction with the government. It may be less expensive for a researcher to convince people to participate in her study if those people expect to benefit greatly from the program. This could lead to the small-scale measured costs being an underestimate of the large-scale costs of convincing a wider population to participate. Participants might even have the same observable characteristics as the general population to the econometrician and policy maker but possess differences that only the researcher can detect. 
ii. Selection bias and sorting: Selection bias and sorting causes the scale up effect through the benefit side when the specific population in a research study is unrepresentative of the greater population because that population has selected into participating. A person may participate in a program if he expects to benefit from it a great deal. When an RCT population consists of many people who evaluated whether to participate only decided to participate if they expected large benefits, that RCT population is likely unrepresentative of the overall population. If a program is scaled up into a policy that everyone must participate in, the program's effect on the specific population who expected great gains may not manifest in the overall population that includes people with characteristics similar to those who did not select in to participate. ${ }^{20}$

iii. Non-random compliance/attrition: Characteristics of the population in an RCT may lead to non-random attrition or compliance both in treatment and control groups. In the case of attrition, people who attrit from an RCT have specific characteristics that influence them to quit. If those characteristics are correlated with benefits from the program, the measured treatment effect of the RCT may fail to capture the effect of the program on those people.

Similarly, even without attrition from a program, different people may comply with a program to various degrees, effectively leading to different people receiving different dosages or even programs. Ensuring participation in and compliance with a program is related to the perceived benefit people expect to gain from a program. Non-random attrition and/or compliance causes an RCT to measure a program's effect on a population with specific characteristics, resulting in a potentially inaccurate measure of program benefit.

In the context of attrition and compliance, an important implication of including costs to the voltage effect literature that has mostly focused on benefits is that having $100 \%$ compliance and $0 \%$ attrition does not necessarily maximize the $\mathrm{BC}$ measure.

iv. Economies/diseconomies of scale in participation costs: Participation costs per individual may decrease or increase from small to large scale, or exhibit economies or diseconomies of scale. If at small scale each participant requires individual effort to be convinced to participate, but at large scale a program policy has a marketing effort with wider reach, per-person participation costs could decrease at scale. At an even larger scale, a policy implemented by the government could have even lower per-participant costs if participation is required.

Alternatively, costs per participant could increase at scale if, in order to compel a wider population to participate, it is more expensive to convince each individual to participate. This is similar to selection into a program--it may be more expensive to convince people to participate if they expect small (or no) benefit from participating. Participation costs can also

\footnotetext{
${ }^{20}$ A more technical description of different evaluation strategies (including the Roy model and Local Average Treatment Effect (LATE)) can be found in Heckman (2010). Importantly, this is a key difference between parameters estimated in framed field experiments versus natural field experiments (see Al-Ubaydli and List, 2013).
} 
change with scale in an another case in which an initial successful RCT increases awareness of a program so it is easier to convince the next group of people to participate. For example, a widespread media campaign could lower participation costs at scale because it would increase awareness of the program.

\section{Insights from the model on representativeness of the population}

A first insight from the Al-Ubaydli et al. (2019) model is that as one liberally changes the importance of being replicated, being published, or having one's research adopted by policymakers, the nature of the scale up effect changes. For example, as the weight scientists place on replicability grows larger, the smaller the scale up effect problem, ceteris paribus. Likewise, decreasing the weight on the scientist's publishing and adoption rewards causes a smaller scale up effect, ceteris paribus. The mechanism underlying such results is that the nonrepresentativeness of the participant pool chosen by the scientist changes as a direct result of the weights of her objective function changing.

These results and related insights from the model lead to several proposals:

PROPOSAL \#2: We should reward scholars for attempting to replicate-tying tenure decisions, public grant money, and the like to replication work (i.e., reward the supply for replications).

PROPOSAL \#3: We should reward scholars for producing initial results that independently replicate - tying tenure decisions, public grant money, and the like to such research (i.e., increasing the demand for replicable work).

PROPOSAL \#4: Scholars finding null results, especially "tight zeros," should report them unabashedly and receive rewards since these contain valuable policy information.

PROPOSAL \#5: Leverage multi-site trials to learn about the variation of program impacts across both populational and situational dimensions. In other words, before scaling understand the program effects across subsets of the general population and characteristics of the situation to understand who should receive the program and where/how it should be implemented and whether it passes a benefit/cost test.

Proposal 5 highlights the import of using the original research design to provide empirical content to the representativeness of the population (and situation, discussed next). For excellent recent discussions see Raudenbush and Bloom (2015) and Weiss et al. (2017). In carrying out such an agenda, the analyst should not only measure average treatment effects, but explore how the treatment effects vary across people. By using appropriate variation in individual-specific characteristics, the design of multi-site trials can provide empirical content into why effects might not scale and give empirical hints about where more research is necessary before scaling (see Supplee et al., 2013; Supplee and Metz, 2015). This emphasis on multi-site trials also applies for situational heterogeneity discussed below.

\section{In Sum:}

The threat posed to the measured BC profile by unrepresentative populations is multi-pronged and it can affect both the benefit and cost components. Al-Ubaydli et al. (2019) pinpoint the 
potential mechanisms through which this threat is at work, and as a first step researchers should make more information available to consumers of their research. Some of these mechanisms, like selection bias and non-random compliance and attrition, are often discussed in the literature. Others, such as researcher choice/bias and (dis)economies of scale in participation costs, have been mostly neglected.

\section{Examples:}

Researcher choice/bias exists in empirical literature in a variety of forms. In an excellent example, Allcott (2015) describes site selection of OPower experiments. The motivation behind much of the selection of sites resulted from preferences of the utilities he worked with, not specifically those of a researcher. Convenience and dedicated targeting of subpopulations-to generate a strong initial proof of concept--were reasons enough to deliberately seek out an unrepresentative sample.

In the context of education, Stuart et al. (2017) analyzed the characteristics of schools and their corresponding districts of those that participated in 11 large-scale rigorous evaluations and found that they differ from target population in terms of size, student performance on state assessments, and location. In other words, unrepresentativeness likely goes beyond population to include unrepresentativeness of situation as well.

Banerjee et al. (2017) describe work that found no effect of fortified salt on anemia rates, despite earlier programs that found that fortified salt reduced anemia rates. They posit that this result occurred because original studies (Banerjee et al., 2015) specifically sought out adolescent women, and that in the wider roll-out the measured treatment effect did not manifest at a larger scale with a broader population. While it remained intact for adolescent women, it was absent for other groups. This represents an example of researchers selecting a target population for early efficacy tests.

Heckman et al. (1998) discuss selection into RCTs and find that the characteristics of subjects who participate can be distinctly different from subjects who do not participate, which is known as randomization bias. This implies that the measured treatment effect of a small-scale program evaluation that compares treatment and control groups that are different than the set of individuals who did not participate will not accurately represent the effect of the program.

In their study of take-up of biofortified crops by farmers, Ogutu et al. (2018) acknowledge the possibility that non-random attrition may affect their treatment effect estimate because the control group and one of three treatment arms had higher attrition rates than the other two. If characteristics that influenced program impact were related to characteristics that led subjects to attrit, measured treatment effect would be a poor representation of the actual treatment effect. To account for this possibility, they use a weighting procedure to control for this in their analysis.

\section{C. Representativeness of the Situation}


Are we extrapolating from the "correct" situation? While much attention has been paid to representativeness of the population (and for good reason), less attention has been paid to formally modeling aspects of the situation. Indeed, data thus far suggest that representativeness of the environment is quite important, and in many cases more important than representativeness of the population (see List, 2004, 2006; 2007a, Levitt and List, 2007). The stakes are considerably increased when we consider that when scaling, we oftentimes, generalize our results to both a population of situations and a population of people when we typically only speak to the issue of the latter. Indeed, one meta-analysis in the field of juvenile recidivism suggests that $50 \%$ of voltage problem is due to administrative fidelity (Lipsey, 1999).

The Al-Ubaydli et al. (2019) framework highlights that the scale up effect can occur on the benefit and/or cost sides when the environment in which an RCT occurs is unrepresentative of the context in which a policy is enacted.

i. Situation selection: Characteristics of a situation conducive to running an RCT-including a high level of control, ability to randomize, hands-on effort--can influence the measured effect of that study. When a program becomes policy, the situation changes-including less control, inability to randomize, and more removed involvement of program experts--which impacts the measured effect of the program. Similar to selection of a population to ensure a large initial result, selection of a situation does not result from ill intent, but rather could result from a researcher seeking out a specific situation to secure future funding in order to further evaluate a program.

The very fact that a program evaluation is an experiment can lead subjects to behave in ways that are not representative of how they would behave in a non-experimental setting. For example, the John Henry effect describes additional effort experimental subjects exert simply because they are in an experiment--they act as if they are in a competitive environment (Horton et al., 2011). The very fact that a situation is an experimental setting influences behavior, and this change in behavior can influence effect measures.

ii. Correct delivery: When a researcher evaluates a program, she is able to measure that the program is being delivered correctly. That control over monitoring is lost at larger scale, which can lead to unmeasured incorrect delivery of a program. If the original study involved a certain delivery, in a new situation when the program is delivered incorrectly one cannot expect the measured treatment effect to mirror that measured at small scale. Delivery of a medicine through an orally ingested pill may have different benefits than the same medicine injected. An in-person curriculum is delivery in a very different context than that same curriculum delivered through online videos.

iii. Correct dosage: Similarly, new situations at scale can lead to incorrect dosage of a program. If an original study involved a certain specified dosage, in a new situation with incorrect dosage the measured treatment effect may change. Too few pills of a certain medicine 
may not have the same benefits as a full round of that medicine. Too few lessons, or lessons in the wrong sequence, could lead to different effects than those originally measured.

iv. Correct program: When a program is tested in an initial RCT, by definition the exact program implemented is the program being tested. When that program is implemented in a new situation, the implementation may effectively be of an entirely different program.

v. Economies/diseconomies of scale in implementation costs: The situation in which a program is originally tested influences the nature of the costs that study measures. From small to large scale, implementation cost per individual, or the material cost of the program, may increase or decrease. Costs per individual may increase if researchers incur unusually low costs given the situation in which they implemented an RCT, including from eager grad students and research assistants who work for no monetary cost. Cost per individual might also increase at scale if political constraints make it especially costly to implement a new, large program. At smaller scale, those bureaucratic constraints may have been smaller or non-existent.

Cost per individual may fall, or exhibit economies of scale, if the situation at large scale allows for bulk production of inputs. When a program's implementation involves some form of technology, there may be high fixed costs to developing the intervention but the cost of administering the program for each additional individual is negligible. The use of technology can also decrease the cost of monitoring the delivery, dosage, and fidelity of program implementation, a situational mechanism through which the scale up effect can increase the $\mathrm{BC}$ profile through the cost side.

\section{Insights from the model on representativeness of the situation}

Several insights from the Al-Ubaydli et al. (2019) model reinforce the import of situational representativeness. For example, the model highlights fidelity as a key reason why results may not scale. The model delivers several results pertaining to how to increase fidelity. First, fidelity is increased if facilitators understand the "whys" behind the intervention effect. This is because understanding the "whys" induces implementors to stay the course when actually rolling out the program. The effort that researchers and overseers exert when trying to maintain fidelity sometimes reflects their taking the time to explain to newer administrators the reasoning behind the intervention.

In this spirit, there is a large literature showing that people are more likely to adhere to instructions when they understand their purpose, and when those issuing the instructions take the time to ensure that people buy in. A good illustration is patient-adherence to medicationwhen physicians wish to maximize the likelihood that their patients take drugs as prescribed, one of the best practices that is grounded in rigorous experimentation is to explain the way in which the drug works to the patient via face-to-face meetings, and to explain the importance of following prescription instructions (Zullig et al., 2013). 
Second, diseconomies (economies) of scale cause a larger (smaller) scale up effect. This result pertains to the cost side and represents a key reason why the $\mathrm{BC}$ metrics might change at scale. The results on situational representativeness lead to several proposals:

PROPOSAL \#6: Ceteris paribus, technology should be encouraged to promote standardization, correct dosage, correct program, etc.

PROPOSAL \#7: Include the original scientist on the implementation team to enhance fidelity, to teach policymakers why the result occurs, and for general consultation

PROPOSAL \#8: Policymakers must understand negotiables and non-negotiables when scaling (a necessary condition from scientists before scaling).

PROPOSAL \#9: Researchers should block on situations when doing experiments, just like we commonly block on individual characteristics in modern experimentation (this will help understand \#8, i.e., scale, human's delivering, correct dosage, program, delivery, incentives, substitutes).

Proposal 6 does not imply to use technology to the detriment of intervention efficacy. Quite the opposite, the proposal suggests that if the researcher can achieve similar (or greater) efficacy when using technology (i.e., ceteris paribus), they should substitute in technology. This discussion raises the aforementioned trade-off that is only possible in the context of BC. Given the goal of maximizing the $\mathrm{BC}$ metric (that could be bounded on the cost side), it is not optimal to maximize benefits (e.g., for example, via high fidelity) if that leads to a much faster increase in costs. Similarly, reducing costs is not optimal if benefits decrease at a faster rate through any of the mechanisms of the scale up effect.

One approach to put Proposal 9 in action is to optimally use multi-site designs (for excellent recent discussions see Raudenbush and Bloom (2015) and Weiss et al., (2017)). In carrying out such an agenda, the analyst not only measures the average treatment effect, but explores how treatment effects vary across sites. By using appropriate variation in site-specific characteristics, the design of multi-site trials can provide empirical content to explain why effects might not scale, and give empirical hints where more research is necessary before scaling.

As aforementioned, Bell and Stuart (2016) describe different treatment effects across experimental sites but they mostly focus on population heterogeneity as its source of variance. However, experimental sites per se are multidimensional in nature where both population and situational unrepresentativeness arise jointly. Therefore, multi-site experimental designs will be key to addressing these two threats to scalability.

\section{In Sum:}

Situational features are key to understanding what to expect at scale and, in practice, understanding what high functioning sites look like plays an important role because these sites can not only provide quality of implementation but also reduce costs at scale. Learning about how characteristics of the situation affects the $\mathrm{BC}$ ratio of an intervention does not only help us address the scale up problem, but also, and more broadly, it can inform us how this ratio 
might change when the policy relevant situation changes dramatically (e.g., changes in regulation).

A related, frequently-encountered manifestation is political opposition, especially when a novel intervention is being implemented. The prevailing regime brings with it significant entrenched interests, which may oppose a novel intervention on the basis of financial interests, or simply because of institutional inertia. Circumventing the barriers erected by opponents in a smallscale experiment might be trivial. Yet at a larger scale, this may require a significant financial outlay, corresponding to diseconomies of scale. Or, in the absence of those outlays (constant per capita administrative effort), the treatment effect will be denuded by counterattacking bureaucrats and other vested interests (in the context of conducting field experiments in firms, see the related examples of an "Adam" in every firm (List, 2011a)).

\section{Examples:}

Situation selection is often not an explicitly obvious mechanism through which the scale up effect occurs. An imperfect example includes Vivalt's (2016) analysis, in which NGO and researcher evaluations find higher effects than government-run RCTs, indicating that evaluations "are rooted in particular contexts." In a similar example, compared to their handson implementation in partnership with an NGO, Bold et al. (2013) find that when the Kenyan government implements a contract teacher intervention, the implementation is much weaker, which results in no program effect. Our theoretical model implies that an implementation led by the government, or any entity that is not the original implementer, can change the program situation and can lead to incorrect delivery of the program generally, and dosage and program more specifically.

August et al. (2006) find that when the situation changed from their initial RCT to the next advanced-stage effectiveness trial, families had reduced engagement in a conduct problems prevention program. They identify this as decreased dosage, which contributes to the lack of replicated outcome measures from small to large(r) implementation.

In their paper on scaling up School-Wide Positive Behavioral Interventions and Supports (SWPBIS), Horner et al. (2014) explicitly acknowledge that "as states gained local training, coaching, and evaluation capacity, the cost of SWPBIS implementation became less expensive per school and more feasible for scaling up on a geographically distributed level." As the program expanded, costs decreased or displayed economies of scale.

In some cases, researchers have directly designed the evaluation to learn about the scale up effect. Kerwin and Thornton (2018) include a novel treatment arm in their evaluation of an education program in Uganda to model the policy-relevant situation. They find large effects of a high-quality, relatively high-cost program, but find that a less expensive program specifically designed to scale is much less effective. In other words, they account for the budget constraint that the government would face if it tried to implement a similar intervention but at a much larger scale. The Teaching at the Right Level (TaRL) program described in Banerjee et al. (2017) includes a treatment arm that involves less oversight by Pratham, the implementing 
NGO. In this particular example, the researchers identified oversight through which delivery or dosage could generate the scale up effect. These two evaluations model the situation at scale, and allow analysis of results to more closely mirror the program that might feasibly be implemented at scale.

A case study in this area is the Tennessee Star program. After promising initial results from the Tennessee STAR randomized state-wide class size reduction, Tennessee implemented Project Challenge to reduce class size in K-3 classrooms in the state's poorest school districts (Hippel and Wagner, 2018). Following an influx of money designated to reduce class sizes, those poorest districts did not actually spend the money to decrease average class sizes. Unsurprisingly, Project Challenge did not result in higher test scores. The Basic Education Program, also in Tennessee, reduced statewide class sizes from 26 to 25 on average. Overall, scores did not improve. Both Project Challenge and the Basic Education Program are examples of the entirely wrong program implemented at scale.

California's statewide implementation of smaller class sizes demonstrated diseconomies of scale in implementation costs (Achilles et al., 1993). Jepsen and Rivkin (2009) examine results of the implementation that forced the state of CA to hire from a larger teacher labor market than ever before. To achieve the smaller class sizes, ${ }^{21}$ California could have incurred greater costs to maintain similar-quality teachers, or continue to pay a similar amount but for lower quality teachers. They find that "the increase in the share of teachers with neither prior experience nor full certification dampened the benefits of smaller classes." When the state of California expanded teacher hiring, they hired less experienced teachers, and the large-scale outcomes of the statewide class size reduction were significantly smaller than the original Tennessee STAR findings.

Banerjee et al. (2017) describe their process of testing Teaching at the Right Level (TaRL) and eventually implementing it as a large-scale policy, and acknowledge that their initial result was crucial to "fostering acceptance of the policy by the government," which underscores that selecting a certain situation (and/or population) for an initial program evaluation can give that program its best shot to help secure future work and funding related to that program.

\section{Spillovers and General Equilibrium}

An important property of the situation that we separate into its own discussion is adequate accounting for spillovers and general equilibrium effects. In some interventions, treating people creates a spillover effect on people in the untreated group. This can be of a positive natureconsider the case of a business ethics course where enrollment is assigned to a random subset of a company's employees. Those who do not enroll are still affected positively by the presence of the enrollees, who act as models for them: the greater the number of enrollees (treated group), the smaller the implied treatment effect when comparing treated to untreated in the research study. If we should scale this treatment, we would expect that the treatment effect at

${ }^{21}$ They did reduce average k-3 class sizes from 30 to 20 
scale will be larger than the original research suggested because in the original research the control group outcomes were inflated, so reduced effect estimates.

A recent example of the import of this effect is found in List et al. (2019), who report that in their measurement of the effects of a pre-K intervention, control children gain from being spatially situated near to treatment children. On average, treatment-to-control spillover effects increase a child's non-cognitive (cognitive) scores by about 1.2 (0.6 to 0.7 ) standard deviations. These spillover effects are localized, decreasing as spatial distance to treated neighbors increased. Their evidence suggests the spillover effect on non-cognitive scores are likely to operate through the child's social network. Alternatively, parental investment is an important channel through which cognitive spillover effects operate. Their results show how the scale up effect can be positive: once scaled, the program will be much more successful than the original researchers claimed (see Fryer et al., 2015, for the original research results).

Alternatively, the scale up effect could be negative due to spillovers: consider an intervention that improves the school performance of students in a given class. The control group in the same class may, upon seeing an initial improvement in the performance of the treated group, feel demoralized, inducing a further deterioration in their performance, and accentuating the treatment effect. In psychology, this is denoted as the "resentful demoralization" effect (Cook and Campbell, 1979; related examples can be found in Schumacher at al. (1994) and Friedlander at al. (1985)). This behavioral affect fits within a broader definition of the John Henry effect (Aldashev et al., 2017), which is most often used to refer to situations where the control group exerts additional effort to overcome a perceived disadvantage of being in the control group.

Relatedly, there could be spillovers within the treatment group (spillovers of people in treatment on others in treatment). This occurs whenever the outcome of those in treatment improves as those around them become treated. Social media access, cell phone use, and any other general outcome that has network effects falls under this category. For example, in List et al. (2019), these effects are especially large for non-cognitive scores. The authors find that on average, a child who was randomized into one of the treatment groups gains about 0.7 standard deviations in cognitive scores and about 1.2 standard deviations in non-cognitive scores through these types of spillover effects.

In the cases of both within- and between-treatment spillover effects, we perceive no general rules of thumb regarding which is more likely. We merely note that it can cause a non-zero scale up effect, and empirical measurement of such impacts is important when considering scaling research findings.

The discussion above explored the issue of spillovers between and within experimental groups, but in both cases, spillovers are restricted to people participating in the experiment. There exists an additional possibility, which involves spillovers to people in the experiment and to those who are not even participating in the experiment, which we denote as "general equilibrium effects." For example, if, as part of a small-scale natural field experiment in an Indian village, 
researchers endow participants with quantities of money that are equal to several multiples of their daily wages, then there is a possibility of significant spillover effects to the village's macroeconomy. In turn, these spillovers might effectively give feedback on the treatment and control groups, resulting in further scale up effects, where the sign may be positive or negative. As an illustration, monetary expansion might cause significant inflation, which would undercut the real income increase experienced by the treated. We do not model such spillovers--instead we alert readers to its existence.

General equilibrium effects, including spillover effects, are important sources of the scale up effect. We include these as part of the situational threats given the unique effects that they potentially have on the $\mathrm{BC}$ metric at scale. General equilibrium effects are changes to the market or system outside the evaluation, while spillover effects are measured as changes in behavior of treatment and/or control groups.

i. Direct spillover treated on treated: When the nature of a program involves benefits that are magnified as more people receive the program, spillovers occur directly from treated people to other treated people. Most clearly when programs include network effects, this type of spillover can change the measured treatment effect as scale increases. If a program's effect increases as more people are in the program, the measured treatment effect in a small-scale RCT could be an underestimate of the effect that program would have if it was implemented with more people.

ii. Direct spillover treated on control: Direct spillover of the treated on control is the effect treated individuals have on outcomes of untreated individuals in an RCT. This occurs when treated individuals interact with untreated people, resulting in control group individuals changing their behavior. This can cause the measured treatment effect of an RCT to over- or under-estimate the treatment effect of a program. This form of spillover could cause a scale up effect if an RCT result fails to take into account the gains in the control group outcomes that occured after a behavior change stemming from interaction with the treatment group. If in a large-scale policy there is a higher concentration of treated individuals who have closer contact with untreated individuals than in a small scale RCT, the measured treatment effect may decrease because the comparison group has benefitted from this direct spillover more than the control group in the RCT, thus diluting the measured effect.

iii. Indirect spillover treated on control: Indirect spillover effects of treated individuals on the control group occur when the control group changes its behavior after indirect influence from the treated group. This indirect influence can come from simple knowledge that the treated group is participating in some program, or news about existence of a program, which could influence even untreated individuals to change their behavior. Beyond these mechanisms, spillover effects can impact costs if, through positive spillovers, more people talk about a program and raise awareness, which may decrease participation costs.

$i v$. General equilibrium, or effect on the nature of the market or system: These are changes to the overall market or system outside a program or policy evaluation. These changes do not manifest at small scale. If a policy alters the value of a certain program outcome, the benefit an individual gains from that program may be relatively small if many more people are also benefiting from the program. For example, more people benefitting from certain 
educational credentials may decrease the individual benefit of that credential if a program leads to many more people earning that credential.

\section{Insights from the model on spillovers and general equilibrium effects}

Several insights from the Al-Ubaydli et al. (2019) model show the import of spillovers and general equilibrium (GE) effects. For example, the model highlights that if there are positive program spillovers from treatment to control then the program will be viewed too pessimistically in the original research design. Alternatively, if there are negative network effects a policymaker should expect the studied program to have smaller effects at scale. Measured spillovers within treatment are similarly intuitive. And, for GE effects, a side result is that when programs are scaled we should expect larger GE effects. The results from the model lead to a proposal:

PROPOSAL \#10: The original researcher should measure and report within- and between- spillover effects, and where applicable measure GE effects, to aid in determining and forecasting total effects of a scaled program.

Putting together our spillover discussion with the other proposals, a general proposal for scholars results:

PROPOSAL \#11: Researchers should backward induct when setting up their original research plans to ensure accurate and swift transference of programs to scale. The checklist should include (at least) all of the above proposals related to their choices as well as a complete cataloguing of both benefits and costs, with estimates of how those will change at scale.

A related issue to the GE effects is availability of similar outside programs. In regards to outside programs, if there are viable substitutes to the intervention, a voltage increase will occur when the program more completely dominates substitutes at scale. In this manner, understanding the available substitute set and modeling its effects is invaluable to understanding program effects at scale (see Kline and Walters, 2016).

In sum:

Field experiments draw our attention to the importance of evaluating programs in a natural environment and spillover effects are an unavoidable phenomenon in the policy relevant world. Our analysis above stresses the import of not only addressing these effects but also relying on theoretical models of spillover to guide experimental design when evaluating program effectiveness. An obvious benefit is to estimate a BC profile that is not affected by scale, or at least understand how scale affects the BC metric. In addition, this approach opens the door for endogenizing spillover effects. In other words, similar to use of technology as a way of sustaining high fidelity and low marginal costs, we can leverage spillover effects to increase the $\mathrm{BC}$ at scale. 
We have emphasized the importance of understanding the policy relevant environment in terms of properties of the population and situation. GE effects pushes for an even deeper understanding because the policy relevant environment is nested in a "market" structure or institution with different agents or entities with their own incentives and dynamic interaction among them. At scale, GE effects capture how the dynamics of this market structure are disrupted and their influence on the BC estimate.

\section{Examples:}

In order to test for spillover effects, researchers sometimes employ a roll-out model in which first only some individuals are assigned to receive treatment, and later the rest of a population is assigned to receive the treatment. This allows for identification of how outcomes change based on how many peers are also treated, or how treated individuals can affect treated and control individuals' behavior.

Positive spillovers from treatment to control include Miguel and Kremer's (2004) study on deworming, which finds that the measured treatment effect of a small-scale deworming evaluation is an underestimate. Untreated individuals also benefit from the intervention if they are in villages with some dewormed individuals. By measuring the exogenous variation of local density of treated students, they are able find that the greater the density, the larger the positive effect on control individuals.

Work in education research finds increased overall access to job training can diminish the effects of specific programs for individuals. ${ }^{22}$ Ferracci et al. (2013) find that when a greater percentage of individuals in a distinct labor market receive job training, the impact for each individual falls because the trained jobseekers are no longer as unique/distinct. Crepon et al. (2013) find that measured treatment effect in a small-scale RCT is an overestimate because at large scale the job placement program negatively affects the control group. Similarly, Heckman et al (1999) report that increased job training overall can crowd out the distinction that training affords an individual when fewer people receive it. A large-scale job training program may alter the overall nature of the market trained job-seekers enter into.

Large program effects can occur in partial equilibrium, but fall in general equilibrium in situations like those found in Buera et al (2012) in which microfinance ${ }^{23}$ efforts at scale are "counterbalanced by lower capital accumulation resulting from the redistribution of income from high-savers to low-savers." Chen and Yang (2019) describe a relatively small-scale experiment in which Chinese college students were provided uncensored internet access. They acknowledge that at a larger scale, the project might elicit a government response that did not register in the original, smaller setting. Similarly, Banerjee et al. (2017) find that political backlash can cause a program to fail.

\footnotetext{
22 This includes Heckman, Lochner, and Taber (1998), Duflo, Dupas, and Kremer (2017), examples of inelastically supplied inputs

${ }^{23}$ Banerjee, Karlan, and Zinman (2015) have a review of microcredit impacts being low.
} 
Gilraine et al. (2018) report that after the CA statewide class reduction policy, teachers and students sorted back from the private to the public school system, which led to some positive gains in outcomes. This general equilibrium effect was not captured in any small-scale setting, but evaluators could conceivably have predicted that change in the perceived quality of schools could have impacted people's decisions about which school to work at or attend.

\section{Scaling and Beyond}

The Al-Ubaydli et al. (2019) model pinpoints areas where scalability is theoretically threatened. Surely, meta-studies can provide further empirical insights. For certain threats, researchers can take preemptive steps to avoid inadvertently suffering from them. For example, trying to select a sample that will be as compliant with instructions as the population that they are supposedly representing. Even in the case of the insoluble components of the scalability problem, such as upward-sloping supply curves for administrator quality (e.g. cost of hiring more administrators of similar quality increases the more you need to hire), understanding the source allows scholars to acknowledge it upfront and test to explore the nature and extent of how that variable will impact the benefit cost relationship at scale.

In sum, we can describe the mechanisms through which these threats manifest through the benefit and/or cost side(s) of the BC profile, and we summarize evidence from existing work. Table 1 summarizes the 3 categories and associated mechanisms through which the scale up effect manifests, including additional mechanisms not directly captured by the model but still relevant for researchers and policymakers:

\begin{tabular}{|l|l|l|}
\hline Categories & $\begin{array}{l}\text { Benefits or } \\
\text { Costs? }\end{array}$ & Mechanism \\
\hline \multirow{3}{*}{ 1. Inference } & Benefit & i. Prior \\
\hline & Benefit & ii. P-value \\
\hline Benefit & iii. Power \\
\hline \multirow{3}{*}{ 2. Population } & Benefit/Cost & i. Researcher choice or bias \\
\hline Benefit & ii. Selection bias and sorting \\
\hline Benefit & iii. Non-random attrition / compliance \\
\hline Cost & iv. Economies/diseconomies of scale in participation costs \\
\hline & Benefit & i. Situation selection \\
\hline Benefit & ii. Correct delivery \\
\hline Benefit & iii. Correct dosage \\
\hline 3a. Spillover and & Benefit & iv. Correct program \\
\hline General Equilibrium & Best & v. Economies/diseconomies of scale in implementation costs \\
\hline & Benefit & i. Direct spillover treated on treated \\
\hline & Benefit & ii. Direct spillover treated on control \\
\hline
\end{tabular}


As a first step in bridging the gap between science and policymaking, we must start by identifying the policy relevant environment described in terms of the target population and situation. This environment can indeed change over time but this cannot be an excuse to implement a research project that does not speak to policymakers. We believe that by identifying and measuring the different mechanisms through which the scale up effect manifests can also help inform decision-makers who need to implement an intervention in a different policy environment. Along these lines, our hope is that Table 1 can be used by researchers as a roadmap to identifying the potential threats and associated mechanisms, and address them when developing their research design. As an extension to Table 1, we present a checklist as a guideline to each one of the stakeholders involved in the creation of knowledge and its policy application.

\section{Checklist}

This paper aims to catalyze a broad community of stakeholders to better understand threats to scale and how to tackle those threats and ensure more effective evidence-based policies. We encourage the research community to update its practices and empower policymakers and practitioners to make more informed decisions. We also aim to educate and encourage funders of research, both public and private, to support and incentivize studies that embrace this approach to the science of scaling. We provide the following list of recommendations to address the threats to scalability.

\section{$\underline{\text { All stakeholders }}$}

$\square$ Science of scaling. Challenge the stakeholders community to demand more empiricism with an eye towards scaling, in which positive results from single RCTs are not only replicated but also tested for scalability.

$\square$ Ensuring co-authorship of studies that include replication can help align incentives among researchers and encourage more replication (Butera and List, 2017)

$\square$ Build infrastructure to facilitate the execution of field experiments with replication purposes

$\Rightarrow$ For example, the Collaborations for Impact in Education (CFI-Ed) initiative by the TMW Center for Early Learning and Public Health at the University of Chicago is a new initiative aimed at establishing a network of replicating sites. By building a network with the explicit goal of replicating educational interventions, CFI-Ed aims to remove some barriers to replication by coauthorship agreements and coordinated research.

$\square$ Incentives. The knowledge creation market has to align the incentives of the agents.

$\square$ Reward researchers for producing results that replicate that replicate with publication, tying tenure decisions, public grant money, and the like to replicated findings (proposal \#2)

$\square$ Reward null results, especially "tight zeros" (proposal \#3) 
$\square$ Policy-relevant environment. For program evaluations with a clear policy goal, scholars, practitioners and policymakers must establish the target policy-relevant environment toward which the scale up problem will be mapped (e.g., where the intervention, if successful, would be implemented at scale), in particular, in terms of population and situation.

$\square$ Broadly, understand the market structure within which this policy relevant environment is nested: the different agents/entities with their incentives.

$\square B C$. In the scale up problem both benefits and costs play a key role. With scaling in mind, program evaluation analysis and interpretation should be done in the context of benefit-cost outcome.

$\square$ Pre-registration. Establish mechanisms to limit bias by making pre-registration a norm for pre-analysis plan.

$\Rightarrow$ For example, the research integrity initiative by Arnold Ventures is an example of funders emphasizing the importance of pre-registration and replication of program evaluations, while Lin and Green (2016) is a similar effort from the research community. Many disciplines have already taken steps toward this goal. $^{24}$

$\square$ Education. Educate the broader community of stakeholders, particularly policymakers, civil servants, practitioners, and funders, to correctly interpret information provided by researchers.

\section{$\underline{\text { Researchers }}$}

$\square$ Policy-relevant environment. With representativeness of population and situation in mind, backwards induct to address the potential threats to scaling with the experimental design. For design, give priority to those mechanisms more likely to contribute to the scale up problem.

$\square$ Pre-registration. Pre-register the experiment detailing the research design and the statistical analyses to be performed. Using the Bayesian framework, be explicit how the prior(s) will be updated based on your results. ${ }^{25}$ (Proposal \#1)

$\square$ Why does a program work? Focus on the theoretical mechanisms underlying the program, beyond a simple A/B testing.

$\square$ Understanding the underlying theoretical mechanisms behind program informs whether the $\mathrm{BC}$ profile will remain at scale and/or in a new environment.

$\square$ Identify and test the non-negotiable core components of the program that are necessary and cannot be adapted. In other words, describe to policymakers why the program works - when local implementers know why the program works, they are more faithful to the original design.

$\square$ Inference. Researchers should be explicit about the program they are providing evidence of effectiveness for, and/or the prior(s) they hope to influence. In particular:

\footnotetext{
${ }^{24}$ For an example, see https://www.socialscienceregistry.org/; https://clinicaltrials.gov/; https://osf.io/

${ }^{25}$ For details of a preanalysis plan (PAP), see Glennerseter (2017).
} 
$\square$ Adjust for MHT when reporting p-values.

$\square$ Maximize the statistical power of an RCT given research budget (i.e., blocked randomization, within-subject design $)^{26}$. Don't implement low powered RCTs.

$\square$ Partner with other researchers in your research topic for replication of results.

$\square$ As an alternative, if the circumstances allow, is to organize the experimental site into independently-run sites. ${ }^{27}$

$\square$ Population. Based on the policy relevant population (i.e., from data), backwards induct so that your experimental design takes this into account.

$\square$ Explain the sampling procedure used to make the sample more representative of the population.

$\square$ Present comparative tables to summarize observable characteristics for the experimental sample and the policy-relevant population. This helps to address researcher choice/bias and selection bias/sorting.

$\square$ Alternatively, address how the heterogeneity of population will affect the BC metric

$\square$ Describe how non-random attrition and compliance affect results. For example, analyze results using intent to treat and include even subjects who did not complete a program in order to more accurately measure benefit of a program that had inconsistent participation.

$\square$ Collect and report participation costs to attempt estimates of economies or diseconomies of scale in participation costs.

Situation. Based on the policy relevant situation, backwards induct so that your experimental design takes this into account. (Proposal \#9)

$\square$ Ask if there are aspects of implementation (whether it affects the benefit or cost side) that will significantly affect the BC measure at scale? (e.g., an inelastically supplied input (Davis et al., 2017))

$\square$ In other words, the policy-relevant situation delivery, dosage, and/or the program may not be faithful the the original implementation. Take these constraints into account in the evaluation or address the costs involved in setting up the "situation" as used in the experiment.

$\square$ Consider economies or diseconomies of scale in implementation costs, the costs of core inputs and infrastructure necessary to the program. Collect and report costs.

Spillover and GE. If in the policy-relevant environment, spillover effects may significantly impact the measured benefits and costs, attempt to experimentally study those effects. (Proposal \#10)

$\square$ Use two-stage randomization design (Muralidharan and Sundararaman, 2015)

\footnotetext{
${ }^{26}$ See Czibor et al. (2019)

${ }^{27}$ See Voelkl et al. (2018) for an argument from the preclinical animal research literature.
} 


\section{Policymakers/Practitioners}

Generalizability of the environment. As a first step, review the accumulated science regarding the $\mathrm{BC}$ measure of the program you are considering.

$\square$ How do the characteristics of the population and situation from those evaluations differ from those of your policy relevant environment? The closer the characteristics of the environment, the more likely results will scale.

$\square$ Identify the areas that will need particular attention

$\square$ For the scale up, involve the original scholars on the implementation team to identify and address the different potential sources that threat scalability (Proposal \#7)

$\square$ Understand negotiables and non-negotiables in the scaling process (Proposal \#8)

When policymakers are evaluating outcomes from research studies, they must understand the characteristics of the situation in which the RCT was implemented and how close those characteristics are to those of the policy-relevant situation.

$\square$ It is easier to scale programs that change only one component at a time.

$\square$ As a rule of thumb, use of technology allows better control on standardization, correct dosage, correct programs, etc. (Proposal \#6)

$\square$ Inference. For this, we recommend that policymakers work closely with researchers or in-house researchers. Policymakers should adopt a Bayesian framework and use RCTs to update their priors about the efficacy of a policy. When considering new policies based on research findings, they need to take into account the three P's to thoroughly evaluate the evidence for the policies. In particular:

$\square$ Be explicit about prior beliefs.

$\square$ Do not rely on statistically significant results of a single study.

$\square$ Ignore results from low powered studies.

$\square$ Interpretation of evaluation results. Carefully interpret results from evaluations. Be discerning and skeptical of accepting 'statistically significant' results from experimental studies at face value.

$\square$ Do not make policy decisions based on one evaluation study. Wait to implement a program at scale until the post-study probability (e.g., the belief that a program is efficacious) is above 0.95 .

- Population and Situation. Policymakers, evaluating outcomes from research studies must pay particular attention to characteristics of the population sample in the RCT and analyze whether those characteristics are representative of their policy-relevant population.

$\square$ Scalability of costs. Analyze how the participation and implementation costs will change in your policy relevant environment.

Are there any potential source of economies/diseconomies of scale in these costs? 
$\square$ In other words, leverage existing infrastructure, favor programs that rely on technology, etc. because the cost component of the $\mathrm{BC}$ ratio is likely to remain constant at scale (i.e., the cost per unit).

$\square$ Not just benefits, but also costs. Research studies that evaluate programs emphasize the importance of high fidelity of the implemented program, delivered effectively at the correct dosage to maximize benefits.

$\square$ Ensuring high fidelity in implementation entails costs so focus on the trade-off between benefits and costs.

$\square$ Why does a program work? Understand why a program works (i.e., how program activities are related to program outcomes). Go beyond a simple A/B testing.

$\square$ Understand the underlying theoretical mechanisms behind program to inform whether the $\mathrm{BC}$ profile can be sustained at scale in a different environment

$\underline{\text { Funders }}$

When funding experimental program evaluations, explicitly take into account the threats to scalability, and how the experimental results would help policymakers to make more informed policy decisions.

What do we know so far and what can we learn? Ask researchers to state their beliefs about the efficacy of the program to be evaluated (i.e., prior) and how the data generated by the study will change this prior.

$\square$ Do not underestimate the value of replication in the large frame of learning the efficacy of a program

$\square$ Pre-registration. Ask researchers to preregister the experiment detailing the research design and the statistical analyses to be performed. ${ }^{28}$

\begin{abstract}
After Scaling
As aforementioned, we view the chain from original research to policy as having three major links: i) funding basic research, ii) providing the knowledge creation market with the optimal incentives for researchers to design, implement, and report scientific results, and iii) developing a system whereby policymakers have the appropriate incentives to adopt effective policies, and once adopted, develop strategies to implement those policies with rigorous evaluation methods to ensure continual improvement.
\end{abstract}

Our work focuses on the middle link. Recent work around sustainable interventions due to, e.g., Komro et al. (2016) and Chambers et al. (2013), highlight the import of the third link and work in the area of the economics of charity (see, e.g., List, 2011b) focus on the first link. While a new economic model for these other areas is beyond the scope of this study, we do have thoughts on treatment measurement of a program once it is actually scaled. This leads to our final proposal:

- PROPOSAL \#12: When the program is actually scaled, the correct empirical approach should be taken to measure efficacy, and continuous measurement should be a priority.

28 The Arnold Ventures is a leader among the funders: https://www.arnoldventures.org 
The gold standard to learn about the scale up effect is to run an RCT at scale. Accordingly, our view is that a first best approach to estimating the effects of the program at scale is to do a large-scale RCT. One can then compare these estimates with the results from the original studies to explore efficacy at scale.

If this approach is untenable, then it is critical to adopt an empirical approach that allows stakeholders to measure its efficacy without unrealistic assumptions. While an exhaustive summary of such approaches is beyond the scope of our work, we point the interested reader to List (2007b), who discusses various empirical approaches to policy evaluation as an empirical spectrum, which includes examples of econometric models that make necessary assumptions to identify treatment effects from naturally-occurring data. Some of these approaches like interrupted time series designs or regression discontinuity analysis can get pretty close in addressing the internal validity that RCTs solve. The myriad of approaches to examine naturally-occurring data each invoke their own assumptions and the analyst should use judgement in what data generation process makes the most sense in the particular environment of interest.

Within this empirical spectrum, quasi-experiments can be interpreted as a midpoint between data generated from experiments and naturally occurring data. In quasi-experiments, identification results from near-random processes (i.e., not directly controlled by the researcher) as opposed to true randomization into treatment and control groups in experiments. Consider a statewide evaluation of a reading support curriculum for $5^{\text {th }}$ graders, and the state government has decided to implement the curriculum only in schools where a simple majority of parents support it and have enough budget to cover the costs. Given this rule, although true randomization by researchers is untenable, a quasi-experiment would leverage it to mimic random assignment by narrowing the sample to schools where the voting results were just below or above simple majority. In this quasi-experimental setup, the causal inference is still not clean because identification comes from the critical assumption that the groups on either side of the simple majority are comparable. However, when true randomization is not possible, too costly or unethical, naturally occurring data from quasi-experiments should be considered if the particular environment is appropriate.

\section{Epilogue}

Experimentation has represented the cornerstone of the scientific method since Galileo pioneered the use of quantitative experiments in the $17^{\text {th }}$ century, allowing him to test his theories of falling bodies. In the centuries since, experimentation has uncovered the foundations of life, the universe, and nearly everything in between.

Much like the physical sciences, the empirical gold standard in the social sciences is to estimate a causal effect. Yet, amidst the complexity of the real world, economists have long worked on approaches that seek to separate cause and effect using regression analysis with naturallyoccurring data. But economists have now taken to heart the old maxim that "correlation doesn't 
imply causation," and have in recent decades sought out a variety of other empirical approaches.

One such alternative that economists have turned to is the experimental model of the physical sciences. Early experimentation was in the lab, where volunteers made economic decisions in a controlled environment (see, e.g., Smith, 1962; Fiorina and Plott, 1978). Over the past few decades, economists have increasingly made use of field experiments to explore economic phenomena, in which they combine realism and randomization to test theories and estimate treatment effects (see, e.g., Harrison and List, 2004).

The approach of using randomization in the field has proven quite effective, as insights gained across labor economics, social policies, the role of market structures, public economics, and nearly every other area have been touched by the field experimental approach. Importantly, in doing so, experimentalists have been able to generate data that tests theories, disentangles mechanisms, and provides intervention treatment effects for policymakers. While such insights are invaluable, the primary focus in this three-decade movement has been on how best to generate data to test theory and estimate intervention effects.

We view this focus as important, yet a shortcoming of the extant literature when it comes to informing policy. In this spirit, what has been lacking is a scientific understanding of whether, and to what extent, we should use the experimental insights for policy purposes? In particular, scholars doing the basic science rarely confront the question of whether the research results scale to larger markets or different settings. And, what is the science behind those expectations?

We denote this general issue as the "scale up" problem, and such a discussion naturally leads to understanding the important threats to scalability and addresses what the researcher can do from the very beginning of their scholarly pursuit to ensure eventual scalability. Of course, we are not the first to think about these issues. We are informed by implementation, prevention, translational, economics, and public health research (see, e.g., Kilbourne et al., 2007; Supplee and Meyer, 2015; Supplee and Metz, 2015; Gottfredson et al., 2015). Existing models of scaling emphasize fidelity of implementation and identification of core components, and work thus far has primarily focused on the benefit-side, or the "voltage drop."

This study augments extant literature by applying economic tools to quantify and clarify expected changes to benefits and costs when a program is scaled. In this manner, we are effectively changing the discussion from voltage, or purely benefit driven, to one in which both benefits and costs are considered. In doing so, 12 proposals naturally result that span researchers, policymakers, funders, and other stakeholders.

Together we view our modest proposals as a start to tackle the most vexing scalability threats. Our framework highlights that there is much work to do, both theoretically and empirically, to deepen our understanding of the scale up problem. We have only taken but one small step in this process, but we trust that the literature will take several larger steps in the future, allowing 
us to be on much more solid ground when we argue that scientific experiments should hold a more prominent place in the policy world. 


\section{References}

Achilles, C. M. (1993). The Lasting Benefits Study (LBS) in Grades 4 and 5 (1990-1991): A Legacy from Tennessee's Four-Year (K-3) Class-Size Study (1985-1989), Project STAR. Paper\# 7.

Aldashev, G., Kirchsteiger, G. \& Sebald, A. (2017). Assignment Procedure Biases in Randomised Policy Experiments. The Economic Journal, 127(602), 873-895.

Akram, A. A., Chowdhury, S., \& Mobarak, A. M. (2017). Effects of Emigration on Rural Labor Markets (Working Paper No. 23929). https://doi.org/10.3386/w23929

Allcott, H. (2015). Site selection bias in program evaluation. The Quarterly Journal of Economics, 130(3), 1117-1165.

Al-Ubaydli, O., \& List, J. A. (2013). On the Generalizability of Experimental Results in Economics: In Frechette, G. \& Schotter, A., Methods of Modern Experimental Economics, Oxford University Press.

Al-Ubaydli, O., List, J. A., LoRe, D., \& Suskind, D. (2017). Scaling for Economists: Lessons from the Non-Adherence Problem in the Medical Literature. Journal of Economic Perspectives, 31(4), 125-144. https://doi.org/10.1257/jep.31.4.125

Al-Ubaydli, O., List, J. A., \& Suskind, D. (2019). The Science of Using Science: Towards an Understanding of the Threats to Scaling Experiments (Working Paper No. 25848).

Al-Ubaydli, O., List, J. A., \& Suskind, D. L. (2017). What Can We Learn from Experiments? Understanding the Threats to the Scalability of Experimental Results. American Economic Review, 107(5), 282-286.

Andrews, I., \& Kasy, M. (2017). Identification of and Correction for Publication Bias (Working Paper No. 23298).

Angrist, J. D., Dynarski, S. M., Kane, T. J., Pathak, P. A., \& Walters, C. R. (2012). Who Benefits from KIPP? Journal of Policy Analysis and Management, 31(4), 837-860.

Ashraf, N., Bandiera, O., \& Lee, S. S. (2018). Losing Prosociality in the Quest for Talent? Sorting, Selection, and Productivity in the Delivery of Public Services (Working Paper).

August, G. J., Bloomquist, M. L., Lee, S. S., Realmuto, G. M., \& Hektner, J. M. (2006). Can Evidence-Based Prevention Programs be Sustained in Community Practice Settings? The Early Risers' Advanced-Stage Effectiveness Trial. Prevention Science, 7(2), 151165.

Banerjee, A., Banerji, R., Berry, J., Duflo, E., Kannan, H., Mukerji, S., Walton, M. (2017). From Proof of Concept to Scalable Policies: Challenges and Solutions, with an Application. Journal of Economic Perspectives, 31(4), 73-102.

Banerjee, A., Barnhardt, S., \& Duflo, E. (2015). Movies, Margins and Marketing: Encouraging the Adoption of Iron-Fortified Salt (Working Paper No. 21616).

Banerjee, A., Karlan, D., \& Zinman, J. (2015). Six Randomized Evaluations of Microcredit: Introduction and Further Steps. American Economic Journal: Applied Economics, 7(1), $1-21$.

Banerjee, A. V., Duflo, E., Imbert, C., Mathew, S. A., \& Pande, R. (2017). E-Governance, Accountability, and Leakage in Public Programs: Experimental Evidence from a Financial Management Reform in India (SSRN Scholarly Paper No. ID 2900178).

Bauer, M. S., Damschroder, L., Hagedorn, H., Smith, J., \& Kilbourne, A. M. (2015). An introduction to implementation science for the non-specialist. BMC Psychology, 3, 32.

Bell, S. H., \& Stuart, E. A. (2016). On the "Where" of Social Experiments: The Nature and Extent of the Generalizability Problem. New Directions for Evaluation, 2016(152), 4759.

Bettis, R.A. (2012). 'The search for asterisks: compromised statistical tests and flawed theories', Strategic Management Journal, vol. 33(1), pp. 108-113.

Bold, T., Kimenyi, M., Mwabu, G., Ng'ang'a, A., \& Sandefur, J. (2013). Scaling up what 
works: Experimental evidence on external validity in Kenyan education. Center for Global Development Working Paper, (321).

Buera, F. J., Kaboski, J. P., \& Shin, Y. (2012). The Macroeconomics of Microfinance (Working Paper No. 17905).

Butera, L., \& List, J. A. (2017). An economic approach to alleviate the crises of confidence in science: With an application to the public goods game (No. w23335). National Bureau of Economic Research.

Button, K. S., Ioannidis, J. P. A., Mokrysz, C., Nosek, B. A., Flint, J., Robinson, E. S. J., \& Munafò, M. R. (2013). Power failure: why small sample size undermines the reliability of neuroscience. Nature Reviews Neuroscience, 14(5), 365-376.

Camerer, C.F., Dreber, A., Forsell, E., Ho, T.-H., Huber, J., Johannesson, M., Kirchler, M., Almenberg, J., Altmejd, A., Chan, T., Heikensten, E., Holzmeister, F., Imai, T., Isaksson, S., Nave, G., Pfeiffer, T., Razen, M. and Wu, H. (2016). 'Evaluating replicability of laboratory experiments in economics', Science, vol. 351(6280), pp. 1433-1436.

Chambers, D. A., Glasgow, R. E., \& Stange, K. (2013). The Dynamic Sustainability Framework: Addressing the Paradox of Sustainment amid Ongoing Change. Implementation Science, 8(117).

Chen, Y., \& Yang, D. Y. (2019). The Impact of Media Censorship: 1984 or Brave New World? American Economic Review, 109(6), 2294-2332.

Cheng, S., McDonald, E. J., Cheung, M. C., Arciero, V. S., Qureshi, M., Jiang, D., ... Chan, K. K. W. (2017). Do the American Society of Clinical Oncology Value Framework and the European Society of Medical Oncology Magnitude of Clinical Benefit Scale Measure the Same Construct of Clinical Benefit? Journal of Clinical Oncology, 35(24), 2764-2771.

Christensen, G., \& Miguel, E. (2018). Transparency, Reproducibility, and the Credibility of Economics Research. Journal of Economic Literature, 56(3), 920-980.

Cook, T. \& Campbell, D. (1979). Quasi-experimentation: Design and Analysis Issues for Field Settings. Boston, MA: Houghton Mifflin.

Cooper, C. L., Hind, D., Duncan, R., Walters, S., Lartey, A., Lee, E., \& Bradburn, M. (2015). A rapid review indicated higher recruitment rates in treatment trials than in prevention trials. Journal of Clinical Epidemiology, 68(3), 347-354.

Crépon, B., Duflo, E., Gurgand, M., Rathelot, R., \& Zamora, P. (2013). Do Labor Market Policies have Displacement Effects? Evidence from a Clustered Randomized Experiment. The Quarterly Journal of Economics, 128(2), 531-580.

Crosse, S., Williams, B., Hagen, C. A., Harmon, M., Ristow, L., DiGaetano, R., ... Derzon, J. H. (2011). Prevalence and Implementation Fidelity of Research-Based Prevention Programs in Public Schools. Final Report. Office of Planning, Evaluation and Policy Development, US Department of Education.

Czibor, E., Jimenez-Gomez, D., \& List, J. A. (2019). The Dozen Things Experimental Economists Should Do (More Of) (SSRN Scholarly Paper No. ID 3313734).

Davies, P. (2012). The State of Evidence-Based Policy Evaluation and its Role in Policy Formation. National Institute Economic Review, 219(1), R41-R52.

Davis, J. M. V., Guryan, J., Hallberg, K., \& Ludwig, J. (2017). The Economics of Scale-Up (Working Paper No. 23925).

Deaton, A., \& Cartwright, N. (2018). Understanding and misunderstanding randomized controlled trials. Social Science \& Medicine, 210, 2-21.

Deke, J., \& Finucane, M. (2019). Moving Beyond Statistical Significance: the BASIE (BAyeSian Interpretation of Estimates) Framework for Interpreting Findings from Impact Evaluations (OPRE Report 2019 35). Washington, DC: Office of Planning, 
Research, and Evaluation, Administration for Children and Families, U.S. Department of Health and Human Services.

Duflo, E., Dupas, P., \& Kremer, M. (2017). The impact of free secondary education: Experimental evidence from Ghana. Massachusetts Institute of Technology Working Paper Cambridge, MA.

Ferracci, M., Jolivet, G., \& van den Berg, G. J. (2013). Evidence of Treatment Spillovers Within Markets. The Review of Economics and Statistics, 96(5), 812-823.

Fiorina, M. P., \& Plott, C. R. (1978). Committee Decisions under Majority Rule: An Experimental Study. American Political Science Review, 72, 575-598.

Freedman, S., Friedlander, D., Lin, W., \& Schweder, A. (1996). The GAIN Evaluation: FiveYear Impacts on Employment, Earnings and AFDC Receipt. New York: MDRC.

Freedman, S., Knab, J. T., Gennetian, L. A., \& Navarro, D. (2000). The Los Angeles Jobs-First GAIN Evaluation: Final Report on a Work First Program in a Major Urban Center.

Friedlander, D., Hoetz, G., Long, D. \& Quint, J. (1985). Maryland: Final Report on the Employment Initiatives Evaluation. New York, NY: MDRC.

Fryer, R. G., Levitt, S. D. \& List, J. A. (2015). Parental Incentives and Early Childhood Achievement: A Field Experiment in Chicago Heights (No. w21477). National Bureau of Economic Research.

Gelman, A., \& Carlin, J. (2014). Beyond Power Calculations: Assessing Type S (Sign) and Type M (Magnitude) Errors. Perspectives on Psychological Science, 9(6), 641-651.

Gilraine, M., Macartney, H., \& McMillan, R. (2018). Education Reform in General Equilibrium: Evidence from California's Class Size Reduction (Working Paper No. 24191).

Glennerster, R. (2017). Chapter 5 - The Practicalities of Running Randomized Evaluations: Partnerships, Measurement, Ethics, and Transparency. In A. V. Banerjee \& E. Duflo (Eds.), Handbook of Economic Field Experiments (Vol. 1, pp. 175-243).

Gottfredson, D. C., Cook, T. D., Gardner, F. E. M., Gorman-Smith, D., Howe, G. W., Sandler, I. N., \& Zafft, K. M. (2015). Standards of Evidence for Efficacy, Effectiveness, and Scale-up Research in Prevention Science: Next Generation. Prevention Science, 16(7), 893-926.

Greenland, S., Senn, S. J., Rothman, K. J., Carlin, J. B., Poole, C., Goodman, S. N., \& Altman, D. G. (2016). Statistical tests, $P$ values, confidence intervals, and power: a guide to misinterpretations. European Journal of Epidemiology, 31(4), 337-350.

Hamarsland, G. D. (2012). Cost-benefit Analysis in Norway. Retrieved from https://www.ntnu.edu/documents/1261865083/1263461278/6_4_Hamarsland.pdf

Harrison, G. W., \& List, J. A. (2004). Field Experiments. Journal of Economic Literature, 42(4), 1009-1055.

Heckman, J. J. (2010). Building Bridges Between Structural and Program Evaluation Approaches to Evaluating Policy. Journal of Economic Literature, 48(2), 356-398.

Heckman, J. J., Ichimura, H., Smith, J., \& Todd, P. (1998). Characterizing Selection Bias Using Experimental Data. Econometrica, 66(5), 1017-1098.

Heckman, J. J., Lalonde, R. J., \& Smith, J. A. (1999). Chapter 31 - The Economics and Econometrics of Active Labor Market Programs. In O. C. Ashenfelter \& D. Card (Eds.), Handbook of Labor Economics (Vol. 3, pp. 1865-2097).

Heckman, J. J., Lochner, L., \& Taber, C. (1998). Explaining Rising Wage Inequality: Explorations with a Dynamic General Equilibrium Model of Labor Earnings with Heterogeneous Agents. Review of Economic Dynamics, 1(1), 1-58.

Hippel, P., \& Wagner, C. (2018). Does a Successful Randomized Experiment Lead to Successful Policy? Project Challenge and What Happened in Tennessee After Project STAR (SSRN Scholarly Paper No. ID 3153503). 
Hitchcock, J., Dimino, J., Kurki, A., Wilkins, C., \& Gersten, R. (2011). The Impact of Collaborative Strategic Reading on the Reading Comprehension of Grade 5 Students in Linguistically Diverse Schools. Final Report. NCEE 2011-4001. National Center for Education Evaluation and Regional Assistance.

Horner, R. H., Kinkaid, D., Sugai, G., Lewis, T., Eber, L., Barrett, S., Dickey, C. R., Richter, M., Sullivan, E., Boezio, C., Algozzine, B., Reynolds, H. \& Johnson, N. (2014). Scaling Up School-Wide Positive Behavioral Interventions and Supports: Experiences of Seven States With Documented Success. Journal of Positive Behavior Interventions, 16(4), 197-208.

Horsfall, S. \& Santa, C. (1985). Project CRISS: Validation Report for the Joint Review and Dissemination Panel. Unpublished manuscript.

Horton, J. J., Rand, D. G. \& Zeckhauser, R. J. (2011). The Online Laboratory: Conducting Experiments in a Real Labor Market. Experimental Economics, 14(3), 399-425.

Hunter, J. E. (2001). The Desperate Need for Replications. Journal of Consumer Research, 28(1), 149-158.

Ioannidis, J. P. A. (2005). Contradicted and initially stronger effects in highly cited clinical research. JAMA, 294(2), 218-228.

Jennions, M.D. and Moller, A.P. (2001). 'Relationships fade with Time: a meta-analysis of temporal trends in publication in ecology and evolution', Proceedings of the Royal Society of London, vol. 269(1486), pp. 43-48.

Jepsen, C., \& Rivkin, S. (2009). Class Size Reduction and Student Achievement The Potential Tradeoff between Teacher Quality and Class Size. Journal of Human Resources, 44(1), 223-250.

Kaplan, D. (2018). Bayesian Inference for Social Policy Research (OPRE Report 2019 36). Washington, DC: Office of Planning, Research, and Evaluation, Administration for Children and Families, U.S. Department of Health and Human Services.

Karlan, D., \& List, J. A. (2007). Does Price Matter in Charitable Giving? Evidence from a Large-Scale Natural Field Experiment. American Economic Review, 97(5), 1774-1793.

Kerwin, J., \& Thornton, R. L. (2018). Making the Grade: The Sensitivity of Education Program Effectiveness to Input Choices and Outcome Measures (SSRN Scholarly Paper No. ID 3002723). Retrieved from Social Science Research Network website:

Kilbourne, A. M., Neumann, M. S., Pincus, H. A., Bauer, M. S., \& Stall, R. (2007). Implementing evidence-based interventions in health care: application of the replicating effective programs framework. Implementation Science: IS, 2, 42.

Kline, P. and C.R. Walters (2016), Evaluating public programs with close substitutes: The case of Head Start," Quarterly Journal of Economics 131(4), $1795\{1848$.

Knechtel, V., Coen, T., Caronongan, P., Fung, N., \& Goble, L. (2017). Pre-kindergarten impacts over time: An analysis of KIPP charter schools. Washington, DC: Mathematica Policy Research.

Komro, K. A., Flay, B. R., Biglan, A., \& Wagenaar, A. C. (2016). Research Design Issues for Evaluating Complex Multicomponent Interventions in Neighborhoods and Communities. Translational Behavioral Medicine, 6(1), 153-159.

Kushman, J., Hanita, M. \& Raphael, J. (2011). An Experimental Study of the Project CRISS Reading Program on Grade 9 Reading Achievement in Rural High Schools. Final Report NCEE 2011-4007. National Center for Education Evaluation and Regional Assistance.

Levitt, S. D., \& List, J. A. (2007). What Do Laboratory Experiments Measuring Social Preferences Reveal About the Real World? Journal of Economic Perspectives, 21(2), 153-174.

Lin, W., \& Green, D. P. (2016). Standard Operating Procedures: A Safety Net for Pre-analysis 
Plans. PS: Political Science \& Politics, 49(3), 495-500.

Lipsey, M. W. (1999). Can Rehabilitative Programs Reduce the Recidivism of Juvenile Offenders? An Inquiry into the Effectiveness of Practical Programs. Virginia Journal of Social Policy \& the Law, 6(3), 611-642.

List, J. A. (2004), "Neoclassical Theory Versus Prospect Theory: Evidence from the Marketplace," Econometrica, (2004), 72(2), pp. 615-625.

List, J.A. (2006), "The Behavioralist Meets the Market: Measuring Social Preferences and Reputation Effects in Actual Transactions," Journal of Political Economy, 114(1), pp. $1-37$.

List, J. A. (2007a), "On the Interpretation of Giving in Dictator Games," Journal of Political Economy, (2007), 115(3), pp. 482-494.

List, J. A. (2007b). Field Experiments: A Bridge between Lab and Naturally Occurring Data. The B.E. Journal of Economic Analysis \& Policy, 6(2 - Advances), Article 85(2), pp. $1-47$.

List, J. A. (2011a). Why Economists Should Conduct Field Experiments and 14 Tips for Pulling One Off. Journal of Economic Perspectives, 25(3), 3-16.

List, J. A. (2011b) "The Market for Charitable Giving," Journal of Economic Perspectives, (2011), 25(2): pp. 157-180.

List, J. A., Shaikh, A. M., \& Xu, Y. (2016). Multiple hypothesis testing in experimental economics. Experimental Economics.

List, J. A., Momeni, F., \& Zenou, Y. (2019). Are Measures of Early Education Programs Too Pessimistic? Evidence from a Large-Scale Field Experiment. Working Paper.

Maniadis, Z., Tufano, F., \& List, J. A. (2014). One Swallow Doesn't Make a Summer: New Evidence on Anchoring Effects. American Economic Review, 104(1), 277-290.

Miguel, E., \& Kremer, M. (2004). Worms: Identifying Impacts on Education and Health in the Presence of Treatment Externalities. Econometrica, 72(1), 159-217.

Muralidharan, K., \& Niehaus, P. (2017). Experimentation at Scale. Journal of Economic Perspectives, 31(4), 103-124.

Muralidharan, K., \& Sundararaman, V. (2015). The Aggregate Effect of School Choice: Evidence from a Two-Stage Experiment in India. The Quarterly Journal of Economics, 130(3), 1011-1066.

Nosek, B.A., Spies, J.R. and Motyl, M. (2012). 'Scientific utopia II. Restructuring incentives and practices to promote truth over publishability', Perspectives on Psychological Science, vol. 7(6), pp. 615-631.

Obama, B. (2013). The Budget Message of the President. Retrieved from https://www.govinfo.gov/content/pkg/BUDGET-2014-BUD/pdf/BUDGET-2014BUD.pdf

Ogutu, S. O., Fongar, A., Gödecke, T., Jäckering, L., Mwololo, H., Njuguna, M., ... Qaim, M. (2018). How to make farming and agricultural extension more nutrition-sensitive: evidence from a randomised controlled trial in Kenya. European Review of Agricultural Economics, 1-24.

Raudenbush, S. W., \& Bloom, H. S. (2015). Learning About and From a Distribution of Program Impacts Using Multisite Trials. American Journal of Evaluation, 36(4), 475499.

Riccio, J. (1994). GAIN: Benefits, Costs, and Three-Year Impacts of a Welfare-to-Work Program. California's Greater Avenues for Independence Program.

Rudd, K. (2008). Address to Heads of Agencies and Members of Senior Executive Service, Great Hall, Parliament House, Canberra. Retrieved from https://pmtranscripts.pmc.gov.au/release/transcript-15893

Schumacher, J., Milby, J., Raczynski, J., Engle. M., Caldwell, E. \& Carr, J. (1994). 
Demoralization and Threats to Validity in Birmingham's Homeless Project. In K. Conrad (Ed.), Critically Evaluating the Role of Experiments (Vol. 1, pp. 41-44). San Francisco, CA: Jossey-Bass.

Smith, V. (1962). An Experimental Study of Competitive Market Behavior. Economics Faculty Articles and Research.

Stanley, T. D., Doucouliagos, H., Giles, M., Heckemeyer, J. H., Johnston, R. J., Laroche, P., ... \& Rosenberger, R. S. (2013). Meta-analysis of Economics Research Reporting Guidelines. Journal of Economic Surveys, 27(2), 390-394.

Stuart, E. A., Ackerman, B., \& Westreich, D. (2018). Generalizability of randomized trial results to target populations: Design and analysis possibilities. Research on Social Work Practice, 28(5), 532-537.

Stuart, E. A., Bell, S. H., Ebnesajjad, C., Olsen, R. B., \& Orr, L. L. (2017). Characteristics of school districts that participate in rigorous national educational evaluations. Journal of Research on Educational Effectiveness, 10(1), 168-206.

Supplee, L. H., Kelly, B. C., MacKinnon, D. M., \& Barofsky, M. Y. (2013). Introduction to the Special Issue: Subgroup Analysis in Prevention and Intervention Research. Prevention Science, 14(2), 107-110.

Supplee, L. H., \& Meyer, A. L. (2015). The Intersection Between Prevention Science and Evidence-Based Policy: How the SPR Evidence Standards Support Human Services Prevention Programs. Prevention Science, 16(7), 938-942.

Supplee, L., \& Metz, A. (2015). Opportunities and Challenges in Evidence-based Social Policy (No. V27, 4).

Tuttle, C. C., Gill, B., Gleason, P., Knechtel, V., Nichols-Barrer, I., \& Resch, A. (2013). KIPP Middle Schools: Impacts on Achievement and Other Outcomes. Final Report. Mathematica Policy Research, Inc.

Tuttle, C. C., Gleason, P., Knechtel, V., Nichols-Barrer, I., Booker, K., Chojnacki, G., ... Goble, L. (2015). Understanding the Effect of KIPP as It Scales: Volume I, Impacts on Achievement and Other Outcomes. Final Report of KIPP's" Investing in Innovation Grant Evaluation". Mathematica Policy Research, Inc.

U.S. Department of Health and Human Services Food and Drug Administration (1998), "Guidance for Industry Providing Clinical Evidence of Effectiveness for Human Drugs and Biological Products," May, Clinical 6.

Vivalt, E. (2016). How much can we generalize from impact evaluations? Working paper.

Voelkl, B., Vogt, L., Sena, E. S., \& Würbel, H. (2018). Reproducibility of preclinical animal research improves with heterogeneity of study samples. PLOS Biology, 16(2), e2003693.

Wacholder, S., Chanock, S., Garcia-Closas, M., El ghormli, L., \& Rothman, N. (2004). Assessing the Probability That a Positive Report is False: An Approach for Molecular Epidemiology Studies. JNCI: Journal of the National Cancer Institute, 96(6), 434-42.

Walsh, E., \& Sheridan, A. (2016). Factors affecting patient participation in clinical trials in Ireland: A narrative review. Contemporary Clinical Trials Communications, 3, 23-31.

Weiss, M.J., H.S. Bloom, N. Verbitsky-Savitz, H. Gupta, A.E. Vigil, and D. N. Cullinan. (2017). "How Much Do the Effects of Education and Training Programs Vary Across Sites? Evidence from Past Multisite Randomized Trials." Journal of Research on Educational Effectiveness $10, \quad 4: \quad 843-876$. https://doi.org/10.1080/19345747.2017.1300719.

Young, N. S., Ioannidis, J. P. A., \& Al-Ubaydli, O. (2008). Why Current Publication Practices May Distort Science. PLOS Medicine, 5(10), e201.

Zullig, L. L., Peterson, E. D., \& Bosworth, H. B. (2013). Ingredients of successful interventions to improve medication adherence. JAMA, 310(24), 2611-2612. 